OPEN ACCESS

Edited by:

Wei Tan,

University of Colorado Boulder,

United States

Reviewed by:

Wael Kafienah,

University of Bristol, United Kingdom James (Jay) Henderson,

Syracuse University, United States

*Correspondence:

Tong-Chuan He

tche@uchicago.edu

Aravind Athiviraham

aathiviraham@bsd.uchicago.edu

Specialty section:

This article was submitted to

Tissue Engineering and Regenerative

Medicine,

a section of the journal

Frontiers in Bioengineering and

Biotechnology

Received: 06 September 2020

Accepted: 08 February 2021

Published: 25 March 2021

Citation:

Zhao X, Hu DA, Wu D, He F, Wang H, Huang L, Shi D, Liu Q, Ni N,

Pakvasa M, Zhang Y, Fu K, Qin KH, Li AJ, Hagag O, Wang EJ, Sabharwal M, Wagstaff W, Reid RR,

Lee MJ, Wolf JM, El Dafrawy M, Hynes K, Strelzow J, Ho SH, He T-C and Athiviraham A (2021) Applications of Biocompatible Scaffold Materials in

Stem Cell-Based Cartilage Tissue

Engineering.

Front. Bioeng. Biotechnol. 9:603444.

doi: 10.3389/fbioe.2021.603444

\section{Applications of Biocompatible Scaffold Materials in Stem Cell-Based Cartilage Tissue Engineering}

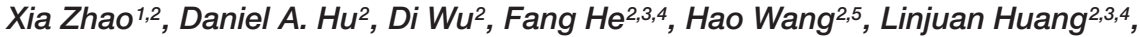

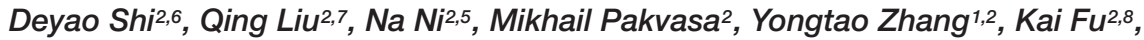

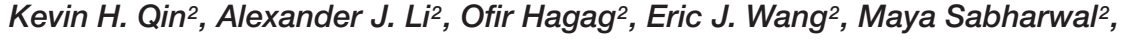 \\ William Wagstaff ${ }^{2}$, Russell R. Reid ${ }^{2,9}$, Michael J. Lee ${ }^{2}$, Jennifer Moriatis Wolf2,

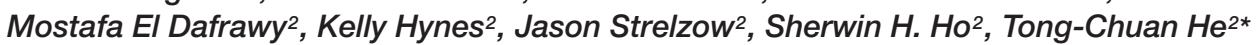 \\ and Aravind Athiviraham ${ }^{2 *}$
}

\begin{abstract}
${ }^{1}$ Department of Orthopaedic Surgery, The Affiliated Hospital of Qingdao University, Qingdao, China, ${ }^{2}$ Molecular Oncology Laboratory, Department of Orthopaedic Surgery and Rehabilitation Medicine, The University of Chicago Medical Center, Chicago, IL, United States, ${ }^{3}$ Department of Nephrology, The First Affiliated Hospital of Chongqing Medical University, Chongqing, China, ${ }^{4}$ Department of Obstetrics and Gynecology, The First Affiliated Hospital of Chongqing Medical University, Chongqing, China, ${ }^{5}$ Ministry of Education Key Laboratory of Diagnostic Medicine, The School of Laboratory Medicine, Chongqing Medical University, Chongqing, China, ${ }^{6}$ Department of Orthopaedic Surgery, Union Hospital of Tongji Medical College, Huazhong University of Science and Technology, Wuhan, China, ${ }^{7}$ Department of Spine Surgery, Second Xiangya Hospital, Central South University, Changsha, China, ${ }^{8}$ Departments of Neurosurgery, The Affiliated Zhongnan Hospital of Wuhan University, Wuhan, China, ${ }^{9}$ Department of Surgery, Section of Plastic Surgery, The University of Chicago Medical Center, Chicago, IL, United States
\end{abstract}

Cartilage, especially articular cartilage, is a unique connective tissue consisting of chondrocytes and cartilage matrix that covers the surface of joints. It plays a critical role in maintaining joint durability and mobility by providing nearly frictionless articulation for mechanical load transmission between joints. Damage to the articular cartilage frequently results from sport-related injuries, systemic diseases, degeneration, trauma, or tumors. Failure to treat impaired cartilage may lead to osteoarthritis, affecting more than $25 \%$ of the adult population globally. Articular cartilage has a very low intrinsic self-repair capacity due to the limited proliferative ability of adult chondrocytes, lack of vascularization and innervation, slow matrix turnover, and low supply of progenitor cells. Furthermore, articular chondrocytes are encapsulated in low-nutrient, low-oxygen environment. While cartilage restoration techniques such as osteochondral transplantation, autologous chondrocyte implantation (ACl), and microfracture have been used to repair certain cartilage defects, the clinical outcomes are often mixed and undesirable. Cartilage tissue engineering (CTE) may hold promise to facilitate cartilage repair. Ideally, the prerequisites for successful CTE should include the use of effective chondrogenic factors, an ample supply of chondrogenic progenitors, and the employment of cell-friendly, biocompatible scaffold materials. Significant progress has been made on the above three fronts in past decade, which has been further 
facilitated by the advent of 3D bio-printing. In this review, we briefly discuss potential sources of chondrogenic progenitors. We then primarily focus on currently available chondrocyte-friendly scaffold materials, along with 3D bioprinting techniques, for their potential roles in effective CTE. It is hoped that this review will serve as a primer to bring cartilage biologists, synthetic chemists, biomechanical engineers, and 3D-bioprinting technologists together to expedite CTE process for eventual clinical applications.

Keywords: articular cartilage, chondrocytes, stem cells, cartilage tissue engineering, scaffold materials, biocompatibility, osteoarthritis

\section{INTRODUCTION}

Articular cartilage, also known as hyaline cartilage, is a unique and durable connective tissue that plays a critical role in physiological mobility by providing nearly frictionless articulation for mechanical load transmission between joints (Figure 1) (Ge et al., 2012). Owing to the scarcity and poor proliferative activity of adult chondrocytes, a lack of vascularization and innervation, a slow matrix turnover, and a low supply of progenitor cells (Hunziker, 2002; Makris et al., 2015), articular cartilage has a very low intrinsic self-regeneration capacity after injury (Moura et al., 2020). Furthermore, the chondrocytes of articular cartilage are entrapped in a lownutrient and low-oxygen environment (Yamagata et al., 2018). Damage to the articular cartilage frequently results from sportrelated injuries, diseases, degeneration, trauma, and tumors. Failure to treat impaired cartilage may lead to osteoarthritis (Muzzarelli et al., 2012), the most common joint disease responsible for pain and disability affecting over a quarter of the adult population (Chen et al., 2017). Cartilage damage usually recovers through scar tissue formation that is primarily composed of fibrocartilage (Ahmed and Hincke, 2010). Hence, it is essential to explore new techniques for articular cartilage regeneration to effectively restore the function of joints.

Ideal cartilage repair aims to restore key properties of the original hyaline cartilage in terms of histological structure and biomechanical functions, which can be only achieved by replacing with healthy cartilage tissue (Alkaya et al., 2020). However, current treatments, including microfracture, autologous and allogeneic osteochondral transplantation, and autologous chondrocyte implantation (ACI), frequently result in the formation of fibrocartilage tissue rather than the ideal native-like hyaline cartilage, leading to serious adverse effects including pain, donor site morbidity, inconsistent long-term effects, and infection (Levy et al., 2013; Solheim et al., 2013; Valderrabano et al., 2017; Moura et al., 2020). ACI is a technique wherein chondrocytes harvested and cultured from healthy cartilage are embedded onto defected cartilage covered with periosteum (Alkaya et al., 2020). The resultant cartilage-like tissue can be integrated with surrounding normal cartilage and function mechanically following regeneration. Currently, ACI is a prevalent clinical method for the treatment of articular cartilage defects, with positive outcomes in patient satisfaction and standard knee scores at short- and mid-term follow-ups (Bentley et al., 2003; Mandelbaum et al., 2007).
While ACI shows promising results in producing hyalinelike tissue (Minas et al., 2016; Sheu et al., 2017; Krill et al., 2018), several drawbacks include donor site morbidity, a shortage in the supply of chondrocytes, chondrocyte dedifferentiation in monolayer culture, and periosteal hypertrophy (Steinwachs and Kreuz, 2007). The biggest challenge of ACI is that chondrocytes are highly prone to transforming into fibroblasts and age considerably faster under in vitro conditions (Gosset et al., 2008). Moreover, implantation of chondrocytes without proper scaffolds often leads to a high likelihood of graft failure, delamination, and tissue hypertrophy (Wood et al., 2006). The low quantity of available cartilage cells, further compounded by their low mitotic activity level, results in difficulty obtaining sufficiently large amounts from cellular cultures (Zylinska et al., 2018; Alkaya et al., 2020). Collectively, while cartilage restoration techniques such as osteochondral transplantation, ACI, and microfracture have been used to repair certain cartilage defects, the overall clinical outcomes are often mixed and undesirable. Better and more efficient cartilage injury repair approaches have to be devised.

Cartilage tissue engineering (CTE) may hold promise to facilitate cartilage repair. Ideally, a successful CTE requires at least three critical parameters: the use of effective chondrogenic factors, an ample supply of chondrogenic progenitors, and the employment of cell-friendly, biocompatible scaffold materials (Green et al., 2015; Mostafa et al., 2019). For the past 10 years, significant progress amounts of basic and translational research have identified biofactors that can promote and/or facilitate chondrocyte differentiation and cartilage maturation, while various sources of mesenchymal stem cells (MSCs) and/or induced pluripotent stem cells (iPSCs) have been characterized as potential chondrocyte progenitor cells (Castro-Vinuelas et al., 2018; Rim et al., 2018). The advent of three-dimensional (3D) bio-printing should further facilitate the progress of CTE (Bishop et al., 2017).

In this review, we briefly discuss potential sources of chondrogenic progenitors, mostly MSCs. We then emphasize on currently available chondrocyte-friendly scaffold materials, including natural and synthetic polymers and extracellular matrix, along with $3 \mathrm{D}$ bioprinting techniques, for their potential roles in effective CTE. Whenever possible, we highlight promising results from in vitro and/or in vivo studies involved in the uses of biofactor-stimulated progenitor cells delivered with biocompatible scaffold materials in this review. It is hoped that the review can serve as a primer to bring cartilage biologists, synthetic chemists, biomechanical engineers, and 3D-bioprinting 


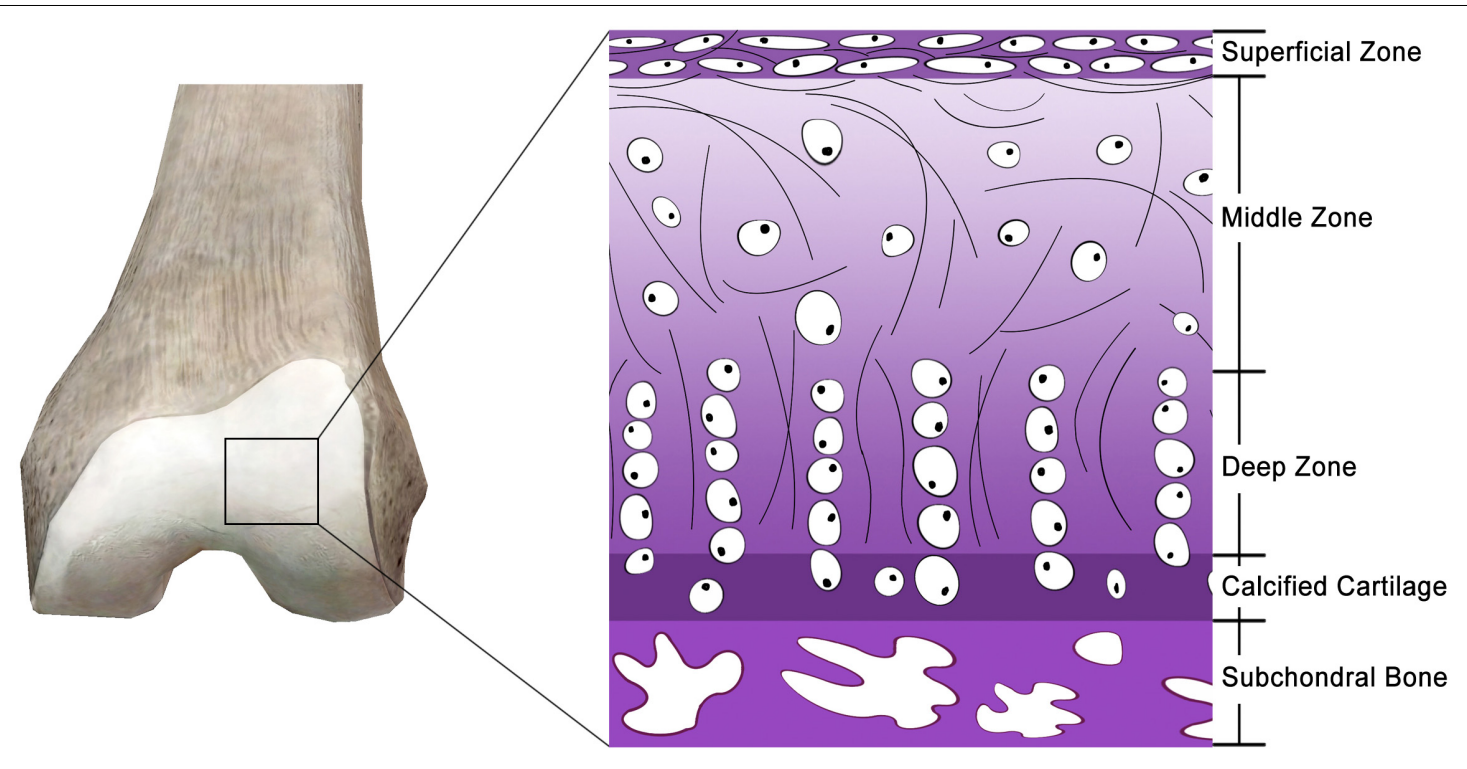

FIGURE 1 | Schematic depiction of articular cartilage and chondrocytes of the joint surface.

technologists together to expedite the CTE process for eventual clinical applications.

\section{MESENCHYMAL STEM CELLS (MSCs) AS AN IMPORTANT CHONDROGENIC PROGENITOR SOURCE FOR CARTILAGE TISSUE ENGINEERING (TE)}

Ideal progenitor cell sources to replace chondrocytes should have the following features: a pool of undifferentiated cells featuring high regenerative potential, unlimited division capacity, selfrenewal capability, easy accessibility, and hypo-immunogenicity (Li Y.Y. et al., 2014). MSCs are multipotent progenitor cells that can self-renew and differentiate into several lineages including bone, cartilage, fat, and muscle (Green et al., 2015; Pittenger et al., 2019; Gomez-Salazar et al., 2020). While the most common used adult source tissues for human MSCs are bone marrow and adipose tissue, MSCs have been identified in numerous connective soft tissues (Pittenger et al., 2019; Gomez-Salazar et al., 2020). As one of the most popular progenitor sources, MSCs have been used in nearly 1,000 clinical trials for diverse indications, ranging from musculo-skeletal defects, disorders of the immune system including auto-immune diseases, to myocardial infarcts (Rastegar et al., 2010; Teven et al., 2011; Beederman et al., 2013; Coalson et al., 2019; Pittenger et al., 2019; Gomez-Salazar et al., 2020; Pakvasa et al., 2021). Nonetheless, MSCs remain a biological enigma, since retrospective derivation in culture has concealed the true native identity of these cells, so their roles in tissue regeneration remain to be fully understood (Gomez-Salazar et al., 2020).

During in vivo cartilage repair experiments, MSCs showed improved cell arrangement, subchondral bone regeneration, and integration compared to mature chondrocytes, suggesting that
MSCs are a suitable alternative for cartilage repair (Li Y.Y. et al., 2014). Although MSCs can be injected intravenously (IV), intraarticularly (IA), or intraperitoneally (IP), the cells ultimately diffuse into the peripheral blood and occupy the non-affected area (Gonzalez et al., 2009; Ra et al., 2011; Liang et al., 2012; Zhang et al., 2014). Efforts have been attempted to transplant MSCs formed in 3D structures, such as seeding in scaffolds, cell aggregates, and sheets (Tasso et al., 2009). Thus, tissue engineering (TE) provides a promising approach for cartilage restoration using MSCs (Chung and Burdick, 2008). The ultimate goal of TE is to develop biological substitutes that can be implanted into the body, supporting tissue remodeling in the frame of a 3D scaffold (Kim W.K. et al., 2019).

The delivery and implantation of MSCs into cartilage defects can be accomplished by seeding MSCs onto different types of scaffolds, which are then introduced into cartilage lesions. An ideal scaffold should contain implanted MSCs and bioactive molecules for chondrocyte differentiation and maturation (Henderson et al., 2004). Growth factors are prime bioactive molecules capable of inducing chondrogenic differentiation of MSCs (Peterson et al., 2000). A major challenge in TE in 3D microenvironments is the need for biomaterial scaffold to promote cell attachment, spreading, migration, proliferation, and differentiation for effective tissue regeneration (Im, 2020; Mohammadinejad et al., 2020). Such biomaterials should have the same mechanical properties as native cartilage, be able to properly integrate with adjacent cartilage, be porous with interconnected pores, have the ability to establish and maintain the desired shape of the regenerated cartilage, and yet adequately biodegrade (Freedman and Mooney, 2019; Alkaya et al., 2020). In the following sections, we summarize the features of commonly used scaffold materials, and preparation techniques for biological scaffolds utilized in either experimental or clinical settings to develop TE for cartilage repair. 


\section{NATURAL POLYMERS AS SCAFFOLDS FOR CARTILAGE TISSUE ENGINEERING}

Natural polymers, such as chitosan, collagen, alginate, silk fibroin, hyaluronan, and gelatin, have been used extensively in TE for cartilage regeneration (Table 1). Due to their superior biocompatibility, excellent biodegradability, minute negative immunological influence, and favorable cellular interaction (Alkaya et al., 2020), many natural materials have been employed to provide a satisfactory bioactive environment and mechanical support to foster the growth of new chondral tissue at defect sites (Bharadwaz and Jayasuriya, 2020). Natural polymers show structural compatibility akin to the biological molecules found in organisms when implanted in vivo, thus reducing the risk of an immune response (Mohammadinejad et al., 2020). Consequently, certain polysaccharides are either non-immunogenic or possess low immunogenicity when compared with synthetic polymers. Moreover, ligands of natural biomaterials can facilitate cell adhesion and promote the activation of various chondrogenic activation pathways (Alkaya et al., 2020).

\section{Chitosan}

Chitosan (CS) has emerged as a strong candidate scaffold for TE applications. Originating from chitin, chitosan is a unique natural polysaccharide with superb properties: high biodegradability, biocompatibility, non-antigenicity, adsorption capabilities, and antimicrobial activity (Giuliani, 2019). Studies have also found no complications, such as inflammation or allergic reactions,

TABLE 1 | Characteristics of the outlined natural polymers for CTE.

\begin{tabular}{|c|c|c|c|c|}
\hline Biomaterials & Characteristics & Advantages & Disadvantages & References \\
\hline Chitosan & $\begin{array}{l}\text { Originating from chitin; } \\
\text { Linear natural carbohydrate biopolymer; } \\
\text { Free amine groups in its backbone } \\
\text { chain; } \\
\text { Slower degradation rate }\end{array}$ & $\begin{array}{l}\text { Biodegradability; Biocompatibility; } \\
\text { Non-antigenicity; } \\
\text { Adsorption capabilities; } \\
\text { Antimicrobial activity; } \\
\text { Promoting chondrogenesis }\end{array}$ & $\begin{array}{l}\text { Low solubility; } \\
\text { Low mechanical } \\
\text { strength }\end{array}$ & $\begin{array}{l}\text { Keller et al. (2017), Giuliani } \\
\text { (2019), Sultankulov et al. (2019) }\end{array}$ \\
\hline Collagen & $\begin{array}{l}\text { Important part of natural cartilage } \\
\text { organic materials; } \\
\text { One of the most abundant proteins in } \\
\text { humans and a major component of } \\
\text { extracellular matrix }\end{array}$ & $\begin{array}{l}\text { Biocompatibility; } \\
\text { Low immunogenicity; } \\
\text { Biodegradability; } \\
\text { Promoting chondrogenesis; } \\
\text { Facilitation of cell ingrowth and } \\
\text { remodeling; } \\
\text { Easy processing }\end{array}$ & $\begin{array}{l}\text { Low solubility; } \\
\text { Low mechanical } \\
\text { strength; } \\
\text { Rapid } \\
\text { biodegradation rate }\end{array}$ & $\begin{array}{l}\text { Lee et al. (2001), Kuroda et al. } \\
\text { (2007), Turk et al. (2018), Li L. } \\
\text { et al. (2019), Marques et al. } \\
\text { (2019) }\end{array}$ \\
\hline Silk & $\begin{array}{l}\text { Extracted from Bombyx mori cocoon; } \\
\text { A biocompatible material found as the } \\
\text { core of a structural protein fiber; }\end{array}$ & $\begin{array}{l}\text { Excellent mechanical properties; } \\
\text { Biocompatibility } \\
\text { Controlled biodegradability; } \\
\text { Lower infection risk; } \\
\text { Easy processing; }\end{array}$ & $\begin{array}{l}\text { Delayed } \\
\text { hypersensitivity; } \\
\text { Initiator of immune } \\
\text { reactions; }\end{array}$ & $\begin{array}{l}\text { Zhang et al. (2010), Wang et al. } \\
\text { (2011), Ma et al. (2018), } \\
\text { Bharadwaz and Jayasuriya } \\
\text { (2020) }\end{array}$ \\
\hline Alginate & $\begin{array}{l}\text { Produced from the cell wall of brown } \\
\text { algae; } \\
\text { Polysaccharide with negative charge; } \\
\text { A cell-friendly gelation }\end{array}$ & $\begin{array}{l}\text { Low immunogenicity; } \\
\text { Biocompatibility; } \\
\text { High abundance resources; } \\
\text { Low prices; } \\
\text { Regulation of the inflammatory } \\
\text { chemokines; } \\
\text { Good chondrogenic potential }\end{array}$ & $\begin{array}{l}\text { Low } \\
\text { biodegradability; } \\
\text { Poor adhesion }\end{array}$ & $\begin{array}{l}\text { Cho et al. (2009), Arlov et al. } \\
\text { (2014), Park and Lee (2014), } \\
\text { Filardo et al. (2018), Li L. et al. } \\
\text { (2019) }\end{array}$ \\
\hline Hyaluronic acid & $\begin{array}{l}\text { A disaccharide unit; } \\
\text { Abundant in the human body, present } \\
\text { in the ECM of the skin, cartilage, and } \\
\text { lenses }\end{array}$ & $\begin{array}{l}\text { Biocompatibility; } \\
\text { High hydrophilicity; } \\
\text { Nontoxicity; } \\
\text { Elasticity; } \\
\text { Anti-inflammatory }\end{array}$ & $\begin{array}{l}\text { Low mechanical } \\
\text { properties; } \\
\text { Rapid enzymatic } \\
\text { degradation }\end{array}$ & $\begin{array}{l}\text { Collins and Birkinshaw (2013), } \\
\text { Gupta et al. (2019), Li L. et al. } \\
\text { (2019), Zheng et al. (2019) }\end{array}$ \\
\hline Gelatin & $\begin{array}{l}\text { Obtained from native collagen via } \\
\text { hydrolysis; } \\
\text { An ideal carrier of proteins, growth } \\
\text { factors, and so on }\end{array}$ & $\begin{array}{l}\text { Biocompatibility; Biodegradability; } \\
\text { High water-solubility; } \\
\text { Cell adhesion }\end{array}$ & $\begin{array}{l}\text { Poor mechanism } \\
\text { properties }\end{array}$ & $\begin{array}{l}\text { Larsen et al. (2006), Li F. et al. } \\
\text { (2017), Echave et al. (2019) }\end{array}$ \\
\hline Platelet-rich fibrin & $\begin{array}{l}\text { Derived from platelet-rich plasma; } \\
\text { Second-generation platelet concentrate } \\
\text { containing abundant growth factors }\end{array}$ & $\begin{array}{l}\text { Greater quantities of growth factors; } \\
\text { Outstanding handling and storage } \\
\text { traits; } \\
\text { Low prices; } \\
\text { Easy preparation }\end{array}$ & $\begin{array}{l}\text { Poor mechanism } \\
\text { properties }\end{array}$ & $\begin{array}{l}\text { Miron et al. (2017), Wong et al. } \\
\text { (2017), Wu et al. (2017), } \\
\text { Barbon et al. (2019) }\end{array}$ \\
\hline Cellulose & $\begin{array}{l}\text { Durable, fibrous, and water-insoluble } \\
\text { substance from plant cell walls }\end{array}$ & $\begin{array}{l}\text { Biodegradability; } \\
\text { Biocompatibility; } \\
\text { Outstanding mechanical properties; } \\
\text { Non-toxic } \\
\text { Low prices; } \\
\text { Natural abundance }\end{array}$ & $\begin{array}{l}\text { Poor mechanism } \\
\text { properties }\end{array}$ & $\begin{array}{l}\text { O'Sullivan (1997), Hubbe et al. } \\
\text { (2017), Isobe et al. (2018), } \\
\text { Tayeb et al. (2018), Dutta et al. } \\
\text { (2019) }\end{array}$ \\
\hline
\end{tabular}


following implantation of CS-based scaffolds (Keller et al., 2017). Due to the existence of free amine groups in its backbone chain, CS can be further modified chemically to introduce useful properties for biomaterial development (Sultankulov et al., 2019). Its hydrophilic structure promotes cell adhesion, proliferation, and differentiation, while its polycationic structure at mild acidity allows for gene delivery through the immobilization of negatively charged DNA, proteins, and enzymes (Sultankulov et al., 2019).

Chitosan is a linear natural carbohydrate biopolymer with configurational similarity to glycosaminoglycans of the ECM for cell-cell adhesion (Rodriguez-Vazquez et al., 2015). CS can present a similar microenvironment, allowing for chondrocyte proliferation and thus inducing chondrogenesis and ECM synthesis (Liu et al., 2017). Its chemical name is (1,4)-2amino-2-deoxy-beta-D-glucan, a copolymer of randomly located $(1 \rightarrow 4)$-2-amino-2-deoxy-d-glucan (d-glucosamine) and $(1 \rightarrow 4)$ 2-acetamido-2-deoxy-d-glucan ( $N$-acetyl d-glucosamine) units (Sultankulov et al., 2019). CS degrades at a slower rate compared to other natural polymers, such as fibrin, gelatin, and collagen (Sultankulov et al., 2019). The physical properties of CS are dependent on its the molecular weight, degree of polymerization, and purity of the product (Tharanathan and Kittur, 2003). Shortcomings of pure CS, especially its mechanical strength, can be rectified by the formulation of CS-based nanocomposite scaffolds, mainly with tricalcium phosphate, collagen, hydroxyapatite, and synthetic polymers (Bharadwaz and Jayasuriya, 2020).

Chondrocytes cultured in CS-alginate beads were shown to express lower levels of inflammatory cytokines (IL-6 and IL-8) and higher levels of cartilage matrix component genes (hyaluronan and aggrecan) in vitro when compared to alginate beads alone (Bhattacharjee et al., 2016). The addition of hyaluronic acid-CS nanoparticles (NPs) to a pellet co-culture of human infrapatellar fat pad (IPFP)-derived MSCs with osteoarthritic chondrocytes led to greater levels of chondrogenic differentiation (Datta et al., 2001). Human IPFP-MSCs seeded on $3 \mathrm{D}$-printed CS scaffolds in chondrogenic media containing TGF- $\beta 3$ and BMP- 6 attached, proliferated, and differentiated into chondrocyte-like cells in the formation of cartilaginous tissue in vitro (Patra et al., 2012). Chitosan was shown to induce human bone marrow MSCs to differentiate into chondroid spheres by activating mTOR/S6K (Li S. et al., 2019). A chitosan-hyaluronic acid-based biometric matrix was shown to provide an appropriate environment, allowing adipose-derived stem cell (ASC) differentiation into cartilage matrix producing chondrocytes (Huang et al., 2019).

Chitosan ( $\mathrm{CH})$, poly (L-lactide) (PLLA), and pectin (PC) compositions have been adapted using the freezing drying method to create polyelectrolyte complex-based porous scaffolds, then crosslinked using 1-ethyl-3-(3-dimethylaminopropyl) carbodiimide (EDC) and a N-hydroxysuccinimide (NHS) solution containing chondroitin sulfate (CS) to mimic the composition and architecture of the cartilage ECM (Mallick et al., 2018). This type of scaffolds exhibited a satisfactory swelling profile and moderate biodegradation, as well as being hemocompatible with sufficient mechanical strength for applications in cartilage tissue regeneration. In order to investigate whether the chitosan gel can adhere to cartilage and bone in various animal bone defects, the a space-filling and cyto-compatible chitosan gel solution was designed and shown to adhere to cartilage and bone in situ, a property that indicated high potential for its use as an arthroscopically injectable vehicle for cell-assisted cartilage repair (Hoemann et al., 2005).

\section{Collagens}

Collagens (COL) are one of the most abundant proteins in humans and a major component of the ECM and have superb biocompatibility, low immunogenicity, interactivity with growth factors and cell adhesion molecules, biodegradability, and facilitation of cell ingrowth and remodeling (Lee et al., 2001). The ECM of articular cartilage is composed of approximately 90\% type II collagen (Spratt and Haycock, 1988). Collagens are comprised of polypeptide chains composed of various amino acids, typically in the tripeptide sequence glycine $\mathrm{X}-\mathrm{Y}$ (X and $\mathrm{Y}$ are frequently proline and hydroxyproline) (Marques et al., 2019), forming a triple helix structure promoting collagen's structural stability and excellent mechanical properties (Silva et al., 2014).

Collagens are found in abundant quantities from fish waste, such as skins, scales, and bones (Senaratne et al., 2006; Ge et al., 2012). Aquatic sources, such as cuttlefish (Nagai et al., 2001), jellyfish (Song et al., 2006), the skin and muscles of oceanic animals, and fish waste (Mahboob, 2015) are regarded as superior to bovine sources (Silva et al., 2014), as there is less concern over the potential transmission of spongiform encephalopathy (Senaratne et al., 2006). Nonetheless, the rapid biodegradation rate of pure collagen scaffolds, their low mechanical strength, and their tendency to cause frequent swelling incentivizes the use of collagen-based composite biomaterials for CTE (Turk et al., 2018).

Collagen-based materials support chondrocyte differentiation and are frequently used in the repair of articular cartilage (Li Y.Y. et al., 2014). When rabbit MSCs and collagen were encapsulated as microspheres, and implanted into the osteochondral defects in an animal model the scaffold promoted spontaneous differentiation of endogenous MSCs into chondrocytes (Yamagata et al., 2018). The implantation of collagen gel and MSCs into an athlete suffering from knee pain resulted in hyaline-like tissue formation and functional recovery of the articular cartilage (Kuroda et al., 2007). The mixture of rabbit chondrocytes with rabbit and rat collagen scaffolds to form neo-RBT (neo-rabbit cartilage) and neo-RAT (neo-rat cartilage) constructs featured cartilage-like repair tissue covering the 5-mm circular, 4-mm deep defects created in the rabbit condyles (Wang et al., 2018).

Collagens exhibit several advantageous characteristics for drug delivery, including high biodegradability and biocompatibility, low toxicity, high efficiency, and a long period of effectiveness (Li L. et al., 2019). However, the interaction level between enzymes and other bioactive substances is weaker in collagen than in hydrophobic polymers (Li L. et al., 2019). Chondrocytes embedded in the hydrogel with type I and II collagens maintained their natural morphology and secreted cartilage-specific ECM, which could be altered by changing the amount of type I collagen (Yuan et al., 2016). Hydrogel formed from HA and type II 
collagen are also able to form in situ scaffolds. Chondrocytes and TGF $\beta 1$, encapsulated in the scaffold, maintained chondrocyte viability and stimulated glycosaminoglycan production, gene expression, and cell proliferation and morphology (Kontturi et al., 2014).

Collagen can also be used as a bioink component of 3-D bio-printing for CTE applications (Kim et al., 2016; Lee et al., 2018; Yang X. et al., 2018). When three different combinations using 3D bioprinting: alginate (SA), alginate/agarose (SA/AG) and alginate/collagen (SA/COL), were tested, the SA/AG bioinks achieved superior tensile strength and compressive modulus, while the SA/COL bioinks featured the best cell viability of the three, as indicated by higher levels of several specific cartilage gene markers (Yang X. et al., 2018). The collagen-based bioinks also led to significantly higher expression levels of specific osteogenic gene markers for human adipose stem cell (hASC) differentiation (Kim et al., 2016). Similarly, Lee et al. (2018) investigated the production of cell-laden collagen structures with a bioink container, and did not find any problems associated with collagen printing when using the most optimal parameters described in the previously mentioned work.

\section{Silk Fibroin}

Silk fibroin (SF) is one of the oldest natural polymers and considered an enticing polymer for various biomedical applications, with an evolutionary history spanning over 380 million years (Ma et al., 2018). Extracted from Bombyx mori cocoon, a mulberry source, SF is a biocompatible material found at the core of a structural protein fiber that is coated with sericin, and has been used in several tissue engineering applications (Bharadwaz and Jayasuriya, 2020). SF extracted from non-mulberry sources, such as the tasar silkworm (Antheraea mylitta), has improved mechanical properties compared to SF isolated from mulberry sources (Kundu et al., 2012). SF-based biomaterials have several advantages over other natural polymers derived from tissues of allogeneic or xenogeneic origins. SFbased biomaterials have a lower infection risk and lower costs due to less complex processing procedures (Ma et al., 2018). Silk fiber purification is typically performed with a simple alkali or enzyme-based degumming protocol, which results in fibrin without sericin (Ma et al., 2018). SF also benefits from the largescale processing infrastructure already established by traditional silk textile industries, further lowering costs (Kundu et al., 2013).

However, certain foreign body responses can be triggered by $\mathrm{SF}$, reminiscent of non-autologous biomaterials of nonmammalian origin (Giesa et al., 2011). It has been suggested the delayed hypersensitivity of silk sutures may relate to the presence of sericin (Du et al., 2011). Nonetheless, further studies must be done to identify the specific source(s) of any immunogenic remnants in silk (Zhang et al., 2010). The biocompatibility of SF-based materials has been well tested when applied in musculoskeletal tissue engineering (MTE) (Meinel and Kaplan, 2012). It was reported that SF 3-D scaffolds activated very mild immune responses after subcutaneous implantation in rats over a period of 1 year; and all genes associated with immune response, including TNF- $\alpha$, IFN- $\delta$, IL-4, IL-6, and IL-13, were held at undetectable expression levels for most types of silk sponges (Wang et al., 2008).
A proper balance of mechanical properties such as breaking strength, modulus, and elongation can make silk a tough, ductile, and attractive material (Vollrath and Knight, 2001). Silk has a strength-to-density ratio up to ten times higher than steel (Gellynck et al., 2008). Such outstanding mechanical qualities provide many potential applications of SF-based materials: its high tensile strength makes it applicable for sutures, while its flexibility is suitable for creating loadbearing scaffolds (Altman et al., 2002). In addition to its good extensibility range, elasticity, strength, and strain hardening, silk's mechanical behavior can also be modified and tuned by altering the protein concentrations and the size and density of pores (Nazarov et al., 2004; Kim et al., 2005).

When implanted, SF products have variable degradation rates determined by the secondary structure of silk formed during regeneration (Wang et al., 2011). Wang et al. (2008) found that water based porous SF scaffolds implanted in rats disintegrated and completely disappeared after 1 year. They also reported silk was bio-resorbable in addition to being biodegradable, suggesting that the host immune system causes degradation of silk and silk material-based scaffolds (Wang et al., 2008). Sengupta et al. (2010) detailed that osteoclasts and osteoblasts were able to invade SF films by expressing metalloproteinases (MMPs). Unlike synthetic biomaterials with faster degradation and less desirable mechanical properties, SF systems are better suited for TE because of their ability to retain strength over extended periods of time in vivo, a trait that is essential given the need for slow degradation and load bearing capacity in TE (Ma et al., 2018). Nonetheless, a truly comprehensive understanding of degradation and the clearing mechanisms of silk prescribes additional investigation, which may benefit the continued development of SF as biomaterial scaffolds (Ma et al., 2018).

\section{Alginate}

Alginate is a natural polysaccharide composed of 1,4-linked D-mannuronic acid (M-block) and L-guluronic acid (G-block) residues (Li L. et al., 2019). It can be harvested from the cell wall of brown algae, and is widely used in TE due to its low immunogenicity, high biocompatibility and availability, and cellfriendly gelation (Rehm and Valla, 1997). Due to these traits, along with its efficient complexation with divalent cations and highly hydrated viscoelastic properties, alginate has been widely implemented to enfold various types of cells into hydrogels (Cho et al., 2009). It has been approved by the US Food and Drug Administration (FDA) for human use as a food additive and wound dressing material. Alginate has a low cost, no cellular toxicity, and easy fabrication of 3D porous scaffolds or cell immobilized beads. However, alginate-only scaffolds showed poor adhesion to anchor-dependent cells (Zehnder et al., 2015). Furthermore, it retains long-term in vivo stability since mammals do not express alginate lyases or other known enzymes with homologous functions, and thus cannot degrade alginate (Lee and Mooney, 2012).

The sulfation of alginate increases its negative charge, promoting electrostatic interactions typical of sulfated GAGs (Arlov et al., 2014). From a biochemical perspective, sulfated alginate is a heparin/heparan sulfate analog, which interacts 
with heparin-binding proteins to inhibit both inflammatory pathways and complement activation (Kerschenmeyer et al., 2017). Moreover, sulfated alginate hydrogels were used as a mitogenic signaling scaffold to induce chondrocyte expansion, while preserving the native cartilage phenotype (Kerschenmeyer et al., 2017).

Alginate is a propitious biomaterial for scaffold-based approaches, possessing good chondrogenic potential and superb biocompatibility (Filardo et al., 2018). Alginate is also dimensionally stable and supports chondrogenic differentiation due to the absence of adhesive domains that may inhibit chondrogenesis (Ma et al., 2012). Alginate gel can be chondroinductive following the embedding of hMSCs (Diduch et al., 2000). Alginate can undergo gentle gelation with multivalent cations like $\mathrm{Ca}^{2+}$, producing hydrogels that showed excellent biocompatibility (Ko et al., 2010). When combined, alginate microspheres and HA hydrogel serve as a composite carrier of MSCs as well as transforming growth factor (TGF) and retains its bioactivity in the scaffold, promoting chondrogenesis of MSCs (Bian et al., 2011). Although it possesses a lower elastic modulus than normal alginate-based hydrogel, the oxidized alginate hydrogel has a higher capability for cartilage repair (Bouhadir et al., 2001). Blending the arginine-glycineaspartic acid (RGD)-modified oxidized alginate, hyaluronate and chondrocytes formed an injectable hydrogel, which expressed the chondrogenesis-related protein and chondrogenic marker gene at 6 weeks after injection (Park and Lee, 2014).

\section{Hyaluronan Acid/Hyaluronan}

Hyaluronan, also known as hyaluronic acid (HA), is a disaccharide unit composed of $N$-acetylglucosamine and Dglucuronic acid (Li L. et al., 2019). It is abundant in the human body, present in the ECM of the skin, cartilage, and lenses. HA does not contain sulfur like other mucopolysaccharides, and the molecular weight varies widely in different tissues. As a major component of the ECM, HA supports cell migration, proliferation, and morphogenesis (Collins and Birkinshaw, 2013). HA can also provide cells with a 3D microenvironment closely resembling natural conditions ( $\mathrm{Li} \mathrm{L}$. et al., 2019), and plays a significant role in wound healing and cell signaling (Toole, 2004). Chondrocytes can firmly attach to such hyaluronanbased matrices (Mohammadinejad et al., 2020). HA also binds to specific receptors expressed in many cells, triggering several intracellular signal events (Cao et al., 2005).

Hyaluronic acid has been used since the 1970s in humans to treat joint pain and other health conditions (Gupta et al., 2019), as well as in various applications such as tissue engineering, regenerative medicine, and clinical practice (Li L. et al., 2019). A chitosan-hyaluronic acid-based biomimetic matrix when used in conjunction with ASC was shown to form articular hyaline cartilage (Huang et al., 2019). It was reported that plateletrich plasma (PRP), rich in various cytokines, proteins, and growth factors, was combined with HA hydrogel to repair critical-size focal cartilage defects in porcine condyles (Yan W. et al., 2020). Exogenous HA prevents the degradation of cartilage while promoting its regeneration and enhancing chondrocyte HA synthesis, reduces proinflammatory mediator production, and suppresses matrix metalloproteinases involved in OA pathogenesis (Li L. et al., 2019). HA gels combined with proteoglycan may be suitable for use as an injectable therapeutic agent, delaying or inhibiting $\mathrm{OA}$ onset following knee injuries (Srinivasan et al., 2012). HA possesses several advantages such as high hydrophilicity, nontoxicity, and biocompatibility (Zheng et al., 2019). Under typical shear rates across two sliding surfaces of articular cartilage, HA viscosity decreased dramatically and became comparable to water due to the shear-thinning effect, ruling out its application for joint lubrication (Jahn et al., 2016). HA degrades in vivo due to it being a natural polymer and also displays variable lubrication and anti-inflammatory capability based on molecular weight (Zheng et al., 2019).

\section{Gelatin}

Gelatin is a fibrous protein composed of a unique sequence of amino acids obtained from native collagen via hydrolysis. Gelatin exhibits good biodegradability and biocompatibility (Aldana and Abraham, 2017), and possesses the ability to create polyionic complexes with charged therapeutic compounds such as polysaccharides, growth factors, proteins, and nucleotides (Larsen et al., 2006), which make gelatin an idea delivery vehicle for a variety of biomolecules (Echave et al., 2019). When MSCs were implanted into rabbit osteochondral defects, gelatin and MSCs were found to be highly biocompatible, without evidence of immune response or lymphocytic infiltration at the site (Yamagata et al., 2018). Gelatin can be used in the construction of scaffolds to improve cell adhesion, infiltration, spread, and proliferation (Sajkiewicz and Kolbuk, 2014).

Gelatin methacryloyl (GelMA) is produced through the reaction of gelatin with methacrylic anhydride (MA) (Van den Bulcke et al., 2000). GelMA hydrogels are notably similar to the ECM, and the mechanical, swelling, and lubricating properties of GelMA hydrogels are reminiscent of natural cartilage (Spiller et al., 2011). Microporous GelMA hydrogels displayed higher rates of proliferation, while GelMA hydrogels without a microporous structure possessed significant advantages in the cartilaginous phenotype (Li X. et al., 2017). A study over the impact of spatial chondrocyte distribution on cartilage defect repair indicated that spatial chondrocyte distribution indeed served an important role in the repair process (Mouser et al., 2018).

Gelatin-based 3D microgels can be utilized to stimulate cell proliferation and bolster the differentiation of encapsulated cells such as stem cells (Li F. et al., 2017). These microgels are capable of shielding the cells from shear-force associated mortality during injection and provide them with a milieu that enhances cell retention within the targeted site (Nichol et al., 2010). Injectable covalently cross-linked gelatin hydrogels have been created recently with the assistance of pendant tetrazine or norbornene click chemistry pairs in modified polymers (Koshy et al., 2016). These gelatin polymers rapidly crosslink together and begin to degrade after injection in vivo, while they facilitate cell viability and transform encapsulated cells into 3D elongated morphologies (Echave et al., 2019). A thermoresponsive gelatin, poly( $N$-isopropylacrylamide)-grafted gelatin (PNIPAAmgelatin) was found suitable as in situ formable scaffold for cartilage repair (Ibusuki et al., 2003). 
Natural and synthetic polymeric electrospun scaffolds have recently gained attention due to their ability to mimic the ECM. One pertinent electrospun fibrous membrane is a hybrid of gelatin and polycaprolactone (GT/PCL), a versatile biomimetic substrate for soft tissue engineering including cartilage (Xue et al., 2013; Zheng et al., 2014). Xue et al. (2013) and Zheng et al. (2014) developed a sandwich model, in which cells were seeded on acellular cartilage sheets layer-by-layer over a titanium alloy mold to generate ear-shaped cartilage. The engineered 3D cartilage using the sandwich model and GT/PCL 70:30 electrospun fibrous membranes proved to be effective (Xue et al., 2013; Zheng et al., 2014). Scaffolds produced using this method also possess superb in situ space-filling qualities in both air and aqueous solutions, without the use of protective barriers. In a separate study, Lin et al. (2019) supplemented mGL scaffolds with bioactive polymers like HA to further optimize them. The ideal ratio was 9:1 of mGL:mHA, generating the best cartilage with high levels of chondrogenesis. The mGL/mHA (9:1) scaffolds also induced bone and cartilage generation after 12 weeks following implantation into rabbit osteochondral defects, highlighting potential future clinical applications (Lin et al., 2019).

\section{Platelet-Rich Fibrin}

Autologous platelet concentrates allow high local concentrations of growth factors while remaining low in cost and complexity. Derived from PRP, platelet-rich fibrin (PRF) is a secondgeneration platelet concentrate containing abundant growth factors such as fibroblast growth factors (FGFs), platelet-derived growth factors (PDGFs), epidermal growth factor (EGF), insulinlike growth factors (IGFs), TGFs, and vascular endothelial growth factors (VEGFs) Wu et al. (2017). Kobayashi et al. (2016) compared the release of growth factors for PRF, PRP, and advanced platelet-rich fibrin (A-PRF), finding that PRP exhibited significantly higher release levels at earlier time points. PRF exhibited a steady release over a 10-day period. A-PRF released significantly greater quantities of growth factors than traditional PRF (Miron et al., 2017). Thus, PRP is optimal for fast delivery of growth factors while PRF and A-PRF are best used when longterm release is desired (Grecu et al., 2019). PRF is composed of leukocytes, cytokines, platelets, and adhesive proteins such as fibronectin, fibrinogen, vitronectin, and thrombospondin-1 (Miron and Zhang, 2018). This blood-derived membrane is also enriched with leukocytes that play a key role in antibacterial immune responses, contributing to wound healing (Dohan et al., 2006; Fioravanti et al., 2015).

Platelet-rich fibrin has drawn attention due to its potential benefits for tissue injury and would healing (Barbon et al., 2019). The affordability, low risk to patients, and ease of preparation all contribute to PRF's status as an ideal scaffold for tissue healing (Maia et al., 2018). Fibrin polymerization results in a 3D cross-linked fibrin matrix (Fioravanti et al., 2015) that can serve as a binding site for growth factors and platelets (Caloprisco et al., 2010; Caloprisco and Borean, 2011). Thus, PRF enhances tissue regeneration by raising growth factor concentration and mimicking the natural process of tissue repair over time (Di Liddo et al., 2018; Miron and Zhang, 2018).
Platelet-rich fibrin was shown to augment proliferation, chemotaxis, and viability of chondrocytes, and induced chondrogenic differentiation in cultured chondrocytes as the expression of markers such as aggrecan and type II collagen was detected (Wong et al., 2017). PRF improved formation and deposition of cartilaginous matrix by cultured chondrocytes (Wong et al., 2017). Spreafico et al. (2009) found that human platelet releasates bolstered ECM synthesis and deposition while maintaining the normal phenotype of chondrocytes. PRF releasate (PRFr) was recently derived from human bloods (Su et al., 2009), and the concentrations of lipids, proteins, and growth factors were higher in PRFr compared to supernatant serum (Burnouf et al., 2012). PRFr was found to upregulate the expressions of aggrecan and type II collagen, heightening the production of proteoclycan and glycosaminoglycan in human OA chondrocytes (Wu et al., 2017). PRF generated a favorable environment for stem cell differentiation and proliferation due to the release of endogenous growth factors (Kazemi et al., 2017).

Platelet-rich fibrin has emerged as a promising biological tool for cartilage regeneration as it carries supraphysiological levels of cytokines and growth factors to injury sites (Barbon et al., 2019). The in situ administration of PDGFs was shown to stimulate in vitro chondrocyte differentiation and proliferation (Brandl et al., 2010), along with promoting in vivo cartilage healing (Fortier et al., 2011). Gaissmaier et al. (2008) reported higher human chondrocyte proliferation rates resulting from the addition of $1 \%$ and $10 \%$ human platelet supernatant in culture, and Akeda et al. (2006) reached a similar conclusion regarding the stimulating effect of $10 \%$ PRP-enriched medium on porcine chondrocyte proliferation (Akeda et al., 2006). Since PRF also contains a multitude of platelet-derived cytokines and growth factors, PRF may be capable of promoting articular cartilage regeneration, providing suitable mechanical properties (Barbon et al., 2019).

Platelet-rich fibrin has recently emerged as a promising nonsurgical means to treat cartilage injuries. Chien et al. (2012) were among the first to demonstrate PRF inclusion in biodegradable fibrin scaffolds as a regeneration matrix to support chondrocyte proliferation and redifferentiation. A culture-free, single-stage approach has been developed, combining PRF with autologous cartilage grafts and negating the need for complex procedures involving in vitro chondrocyte expansion (Wu et al., 2017). In a clinical study, a polymer-based implant was combined with PRF glue and used to treat patients (McDermott, 2019). The procedure was safe and suitable for patients suffering from full-thickness chondral lesions on the patella resulting from microfractures (McDermott, 2019). Thus, PRF prepared from autologous origins to reduce pathogen transmission and immune rejection risks may open the door for its use in regenerative medicine (Barbon et al., 2019).

\section{Cellulose}

Cellulose is a durable, fibrous, and water-insoluble substance from plant cell walls (Dutta et al., 2019), although it can be also produced by some animals (e.g., tunicates), fungi, and bacteria (O'Sullivan, 1997; Eichhorn et al., 2005). Some bacterial genera, such as Pseudomonas, Agrobacterium, Gluconacetobacter, 
Sarcina, and Rhizobium can synthesize bacterial cellulose (BC) from glucose and other carbon sources (Dutta et al., 2019). Bacterial cellulose has been tested as naturally occurring 'nanomaterial' scaffolds (Dutta et al., 2019). The micro-crystalline structure and natural synthesis of cellulose as an individual molecule are critical for forming as a linear chain of glucosyl molecules and self-assemble at the biosynthesis site (McNamara et al., 2015). BC did not solicit the activation of proinflammatory cytokines during in vitro macrophage screening, while stimulating type II collagen biogenesis (Svensson et al., 2005). BC was indeed found to be a novel in vivo degradable scaffold for chondrogenesis (Yadav et al., 2015).

Two distinguished regions of cellulose fibrils are the crystalline and amorphous parts. The chemical processes can be used to produce cellulose nanocrystals (CNCs) by isolating crystalline regions (Tayeb et al., 2018), although mechanical treatments produce cellulose nanofibrils (CNFs) (Moon et al., 2011). Recent use of CNFs and CNCs with nanoscale lateral dimensions has drawn attention, due in part to their natural abundance and biodegradability along with unrivaled flexibility and stiffness, low density, unique rheology, and large aspect ratio (Moon et al., 2011; Lavoine et al., 2012; Hubbe et al., 2017). Cellulose nanoparticles (CNs) refers to all types of cellulose nanomaterials collectively, and are beneficial as substitutes for synthetic petroleum-based adhesives and binders due to their special physiochemical features (Tayeb et al., 2018).

Three-dimensional structuring of bacterial cellulose in an interwoven, translucent, gelatinous, nano-fibrous network of linear polysaccharide polymers occurs at static conditions, as displayed in Gorgieva and Trcek (2019). Compared to cellulose from vegetal sources, bacterial cellulose exhibits extraordinary mechanical characteristics, such as flexibility (Sriplai et al., 2018) and soft-tissue-like stress-strain behavior (Morseburg and Chinga-Carrasco, 2009), along with high levels of crystallinity and water-holding capacity. However, bacterial cellulose is unable to trigger cell attachment or control porosity, and degrades very slowly (Gorgieva and Trcek, 2019). To counteract these drawbacks, chemical and physical modification have been applied both in situ and ex situ (Gorgieva and Trcek, 2019). Changes to culture media, carbon sourcing, and the inclusion of additional materials occurred in situ; physical and chemical treatment of formed BC occurred ex situ (Gorgieva and Trcek, 2019). Bacterial cellulose also features high-purity and net-like morphologies akin to human collagen, benefitting applications in artificial skin, vascular grafts, dental implants, tissue-engineering scaffolds, medical pads, drug delivery, and artificial bone and cartilage creation (Gorgieva and Trcek, 2019).

Cellulose can be used to produce hydrogels with diverse structures and properties due to its abundance of hydroxyl groups (Isobe et al., 2018). Cellulose gel benefits greatly from favorable mechanical properties, thermostability, and biocompatibility, all of which combine to provide it with stiffness (Kobayashi et al., 2014), thermostability (Tsudome et al., 2009), medical applicability (Klemm et al., 2011), and high resistance upon solvent exchange of medium (Isobe et al., 2011). BC is a gel-like substance known as "pellicle," synthesized by Gluconacetobacter xylinus. Despite its excellent mechanical properties (Nakayama et al., 2004) and biocompatibility (Klemm et al., 2011), BC suffers from poor moldability as a result of biological synthesizing activity, restricting it solely to either tube-form or plate-form. In contrast, regenerated cellulose $(\mathrm{RC})$ retains high moldability due to its preparation using a molecular dissolution and coagulation process (Isobe et al., 2018).

\section{SYNTHETIC POLYMERS AS SCAFFOLDS FOR CARTILAGE TISSUE ENGINEERING}

Synthetic polymers degrade slower than natural polymers due to their higher chemical strength derived from hydrolysable moieties, leading to an extended lifespan in the human body (Table 2) (Hoshikawa et al., 2006). Synthetic materials allow for improved control over mechanical and structural features (Alkaya et al., 2020), and can be easily formed into desired shapes. In fact, synthetic materials such as polyurethane (PU), polylactic acid (PLA), polycaprolactones (PCL), and poly(lactideco-glycolide) (PLGA) all have high utility as a result of their special properties (e.g., plasticity, degradation rate, and mechanical characteristics) (Ma et al., 2018). Another benefit to synthetic polymers is their immunological inertia, reducing the risk of pathogen transmission (Wang et al., 2011; Yang et al., 2014). These features, combined with their capacity for chemical and mechanical modification and their low degradation rate, pose a significant benefit (Zylinska et al., 2018). However, their use is limited by their harmful acidic degradation products (Lee and Shin, 2007; Camarero-Espinosa et al., 2016; Liu et al., 2016). Other drawbacks include weaker cellular interactions and inadequate intercellular signal transmission compared to natural media (Ge et al., 2012). The polyacid breakdown products also pose a risk of local $\mathrm{pH}$ increases at implantation sites (Stoop, 2008). The most commonly used synthetic polymers are currently polyglycolic and PLAs, which are especially commonplace in medical applications (Hoshikawa et al., 2006; Ma et al., 2018).

\section{Polyglycolic Acid (PGA)}

Polyglycolic acid (PGA) is a linear, crystalline hydrophobic polyester (Zwingmann et al., 2007). Naturally, hydrolysis of PGA causes its bulk degradation to glycolic acid (Athanasiou et al., 1996). This type of polymer includes poly(hydroxyortho esters) like PLA, PGA, and their copolymers (PLGAs). PGA nonwoven fiber scaffold became widely used to engineer various types of soft tissues, including cartilage (Schaefer et al., 2000), tendon (Deng et al., 2009), blood vessel (Zhang et al., 2007), peripheral nerve and skin (Suzuki et al., 2016). However, the released acidic degradative products of these scaffolds are a major disadvantage that could affect their biocompatibility with seeded cells and host tissues once they are implanted in vivo (Lin et al., 2017). MSCs cultured on PGA scaffolds under the effect of LE135, a low molecular weight synthetic inhibitor of the retinoic acid receptor, generated dose-dependent cartilage formation (Ahmed and Hincke, 2014). A composite scaffold composed of PGAhydroxyapatite (PGA-HA) and autologous MSCs was tested in a rabbit model, resulting in hyaline cartilage and subchondral bone formation (Zhou et al., 2008). 
TABLE 2 | Characteristics of the outlined synthetic polymers for CTE.

\begin{tabular}{|c|c|c|c|c|c|}
\hline Biomaterials & Symbol & Characteristics & Advantages & Disadvantages & References \\
\hline Poly(glycolic acid) & PGA & $\begin{array}{l}\text { Linear, crystalline } \\
\text { hydrophobic polyester; } \\
\text { Semicrystalline polymer; } \\
\text { Insoluble in most organic } \\
\text { solvents }\end{array}$ & $\begin{array}{l}\text { Biocompatibility; } \\
\text { Availability; } \\
\text { Easy processing; } \\
\text { Composited with other biomaterials }\end{array}$ & $\begin{array}{l}\text { Release of acidic } \\
\text { degradation products; } \\
\text { Poor cell adhesion; } \\
\text { Fast biodegradability; } \\
\text { Low mechanical } \\
\text { properties }\end{array}$ & $\begin{array}{l}\text { Klein et al. (2005), Zwingmann } \\
\text { et al. (2007), Nakao et al. } \\
\text { (2017), Birru et al. (2018) }\end{array}$ \\
\hline Poly(lactic acid) & PLA & $\begin{array}{l}\text { Polyesterification reaction } \\
\text { production of lactic acid; } \\
\text { Lower crystallinity and } \\
\text { hydrophilicity than PGA; } \\
\text { Four different forms }\end{array}$ & $\begin{array}{l}\text { Biocompatibility, controllable } \\
\text { biodegradability; } \\
\text { Low toxicity and viscosity; } \\
\text { Favorable mechanical properties; } \\
\text { Thermostability; } \\
\text { Thermoplasticity }\end{array}$ & Poor cell adhesion & $\begin{array}{l}\text { Li et al. (2006), Zwingmann } \\
\text { et al. (2007), Lopes et al. } \\
\text { (2012), Revati et al. (2017), } \\
\text { Smieszek et al. (2019), Szyszka } \\
\text { et al. (2019), Marycz et al. } \\
\text { (2020) }\end{array}$ \\
\hline Poly(ethylene glycol) & PEG & $\begin{array}{l}\text { An amphiphilic polymer that } \\
\text { cannot be recognized by } \\
\text { the immune system }\end{array}$ & $\begin{array}{l}\text { Biocompatibility; } \\
\text { Biodegradability; } \\
\text { Non-immunogenic; } \\
\text { Promoting chondrogenesis; } \\
\text { Great flexibility; } \\
\text { Low polydispersity }\end{array}$ & Poor cell adhesion & $\begin{array}{l}\text { Karim et al. (2016), Ding and Li } \\
\text { (2017), Cheng et al. (2018), } \\
\text { Cheng H. et al. (2019), Li et al. } \\
\text { (2018), Wang et al. (2019) }\end{array}$ \\
\hline Poly- $\varepsilon$-caprolactone & PCL & $\begin{array}{l}\text { Semi-crystalline; } \\
\text { A synthetic polyester } \\
\text { polymer }\end{array}$ & $\begin{array}{l}\text { Biocompatibility; } \\
\text { Biodegradability; } \\
\text { Elasticity; } \\
\text { Excellent mechanical properties; } \\
\text { Thermoplastic }\end{array}$ & $\begin{array}{l}\text { Poor hydrophilicity; } \\
\text { Poor cell adhesion }\end{array}$ & $\begin{array}{l}\text { Ousema et al. (2012), Sousa } \\
\text { et al. (2014), Theodoridis et al. } \\
\text { (2019), Venkatesan et al. (2020) }\end{array}$ \\
\hline
\end{tabular}

Polyglycolic acid has been successfully used in auricular and laryngotracheal cartilage repair (Klein et al., 2005; Nakao et al., 2017). In a three-PGA-layer construct sandwiched around polypropylene, simulating a 3-D auricular structure, greater cartilage regeneration and angiogenesis were found around the implant (Klein et al., 2005; Nakao et al., 2017). These composite scaffolds were demonstrated to guide MSCs toward cartilage repair, an improvement over microfracturing alone (Erggelet et al., 2009). Klein et al. analyzed the chondrogenic potential of freeze-dried polyglycolic acid-hyaluronan (PGA-HA) implants with preloaded MSCs in vitro using a rabbit model and found that MSC-laden PGA-HA scaffolds possess chondrogenic potential and hold promise for stem cell-mediated cartilage regeneration (Klein et al., 2005).

One major shortcoming of PGA materials is the release of acidic degradation products that weaken biocompatibility and trigger inflammatory response. To overcome these shortcomings, PLA/PGA composites have been featured in multiple studies, generating general (Saroia et al., 2018) or anatomic shapes (Lam et al., 2020), and were created by coating fibrous PGA meshes with solutions of PLA in methylene chloride, then evaporating the solvent to deposit PLA on the meshes (Lam et al., 2020). Scaffolds created using this method have been proven to be conducive to cartilage generation both in vitro and in vivo (Birru et al., 2018).

\section{Polylactic Acid (PLA)}

Polylactic acid is a linear polyester with lower crystallinity and hydrophilicity than PGA (Zwingmann et al., 2007). PLA fibrous scaffolds showed a robust structure and supported the highest proliferation rate of seeded MSCs in physiological solutions ( $\mathrm{Li}$ et al., 2006). Constructs of MSCs seeded into PLA were investigated in a rabbit model and were shown to form hyaline-like cartilage tissue (Ahmed and Hincke, 2014). Biomaterials composed of PLA polymers are suggested as an engineered scaffold for a variety of medical applications (Marycz et al., 2020), such as bone, cartilage, and peripheral nerve regeneration (Grzesiak et al., 2015; Marycz et al., 2016; Smieszek et al., 2019).

Polylactic acid benefits from its thermostability, slow degradation, good biocompatibility, and low toxicity (Lopes et al., 2012; Li et al., 2015). Furthermore, PLA is known for its low viscosity and good thermoplasticity, making it an outstanding material for 3D printing (Coppola et al., 2018; Dizon et al., 2018). PLA has been approved by the US FDA for clinical use to treat multiple medical conditions, including several orthopedic conditions (Tyler et al., 2016). PLA-based composites with nanohydroxyapatite (nHAp) are highly cell-compatible and are excellent scaffolds for modulating proliferation, viability and differentiation of progenitor cells (Smieszek et al., 2019; Szyszka et al., 2019). The use of P. purpureum in PLA matrices as a reinforcement filler offers many benefits. It leads to the production of biocomposites with favorable mechanical characteristics and controllable biodegradability (Revati et al., 2017).

\section{Poly(Ethylene Glycol) (PEG)}

Poly(ethylene glycol) (PEG) is a water soluble polymer that cannot be recognized by the immune system (Cheng et al., 2018), and exists in a variety of structures, including dendritic-like, comb-like, linear, 3-arm, and 4-arm (Karim et al., 2016; Ding and Li, 2017). PEG is typically used to label polymer chains with a molecular weight $<20000$, while poly(ethylene oxide) (PEO) is the term used for polymers with a higher molecular weight ( $\mathrm{Li}$ et al., 2018). PEG clears from the body rapidly and has been approved for a myriad of biomedical applications. Furthermore, 
PEG is capable of transferring these traits to other molecules it is covalently bound to, reversing their toxicity or solubility (Cheng et al., 2018; Li et al., 2018). Cryogelation methods can also be used to create macroporous networks of PEG with interconnected pores in CTE (Cheng H. et al., 2019).

Edward Semple et al. (2016) carried out a large-scale synthesis of linear heterobifunctional PEGs through ringopening polymerization (ROP) of ethylene oxide (EO) from four initiators composed of azide, alkyne, protected alcohol $(O$ trityl), and protected amine (N-dibenzyl). Amphiphilic PEGbased films produced from crosslinking pure amphiphilic PEG copolymers can be modified to alter their mechanical properties by changing the type and quantity of soft and hard segments and adjusting the hydrophilic/hydrophobic ratio (Ji D. et al., 2018; Liu et al., 2018). Soft segments are usually polyesters like PLA and PCL or polyethers such as PEG, which exhibit low glass transition temperatures. Hard segments are typically composed of a chain extender, which links soft and hard segments together by hydrogen bonding (Ji D. et al., 2018).

Poly(ethylene glycols) are hydrolytically non-degradable polymers (Janda and Han, 1996; Gravert and Janda, 1997). and thus minimally metabolized in the body with most polymer chains cleared by the liver $(>30 \mathrm{kDa})$ or kidneys $(<30 \mathrm{kDa})$. PEGs can be readily altered by adding various terminal end groups, such as vinyl ether, allyl ether, or acrylate methacrylate, forming PEG networks. These networks can be made degradable by inserting degradable blocks or crosslinkers (Jain et al., 2017). As such, the degradability and hydrophilicity of polymers can be enhanced via inclusion of PEGs. Because degradation is driven by hydrolysis, hydrophilic PEG content and degradation rate are directly linked (Kutikov et al., 2015).

The fabricated PCL-PEG-PCL (PECE) films seeded with ASCs were able to trigger cell adhesion and proliferation for cartilage formation (Fu et al., 2016). After implanting ASC/PECE films in rats, satisfactory tissue formation was observed (Fu et al., 2016). Saghebasl et al. (2018) developed the thermosensitive and injectable hydrogel PNIPAAm-PECEPNIPAAm/gel. In comparison to PECE/gel, the inclusion of PNIPAAm raised porosity and increased the swelling ratio, benefitting cell attachment into the scaffold. The PNIPAAmPECE-PNIPAAm/gel composite is suitable for in vivo use at physiological temperatures $\left(37^{\circ} \mathrm{C}\right)$ and also found to induce chondrocyte cell growth, expressed cartilage-specific ECM genes, and provided a higher cell survival rate than the PECE/gel composite (Wang et al., 2019).

\section{Polycaprolactone (PCL)}

Synthetic semi-crystalline PCL has recently gained significant attention due to its mechanical strength, elasticity, biodegradability, and biocompatibility (Theodoridis et al., 2019). The FDA approved aliphatic polyester poly( $\varepsilon$-caprolactone) (PCL) presents significant advantages, as the low immunogenic biodegradable compound can mimic the anisotropic and viscoelastic biomechanical features of the articular cartilage (Venkatesan et al., 2020). PCL is also easily processed and chemically versatile, with high structural and thermal stability (Domingos et al., 2012). Its degradation products are also harmless to the human body because they can be metabolized in the tricarboxylic acid cycle (Moura et al., 2020).

While PCL scaffolds can support stem cell differentiation and proliferation, its hydrophobic profile inhibits cellular attachment and thus hurts its suitability in tissue engineering (Sousa et al., 2014). Researchers have attempted to use chemical and plasma treatments together with blending of hydrophilic materials and the ECM to increase the PCL's hydrophilicity (Sousa et al., 2014; Chen et al., 2016; Silva et al., 2017). PCL-based fibrous scaffolds exhibit high structural integrity following incubation in a physiological solution, and support desirable cell responses of the seeded MSCs (Liu et al., 2006). Chondrogenic differentiation of MSCs on oriented nanofibrous PCL scaffolds was explored in an in vitro study. MSCs cultured onto electrospun and oriented PCL scaffolds (500 or $3000 \mathrm{~nm}$ fiber diameter) induced chondrogenic markers and enhanced the chondrogenic differentiation of MSCs (Wise et al., 2009).

A 3D woven PCL scaffold seeded with MSCs was fabricated and found to promote chondrogenesis while maintaining favorable mechanical characteristics, without eliciting proinflammatory cytokine (Ousema et al., 2012). A biodegradable PCL nanofibrous scaffold seeded with MSCs successfully repaired a swine model of full-thickness cartilage defects (Li et al., 2009). Poly(vinyl alcohol)/polycaprolactone (PVA/PCL) nanofiber scaffolds seeded with BM-MSC were found to support MSC chondrogenic differentiation and proliferation in vitro and repaired rabbit full-thickness cartilage defects (Shafiee et al., 2011).

\section{DECELLULARIZED EXTRACELLULAR MATRIX (dECM) MAY PROVIDE SUPERIOR TISSUE-SPECIFIC MATRIX MICROENVIRONMENT FOR TISSUE ENGINEERING}

Cartilage features chondrocytes and extracellular fibers embedded in a matrix, providing strength and acute pliability. The ECM therefore serves as a microenvironment for chondrocytes, and the preservation of stable cellular phenotypes depends on the interaction of cartilage with their pericellular matrix (Gentili and Cancedda, 2009). ECM metabolism also plays an essential role in skeletal tissue development and regeneration/repair, especially in orthopedic diseases and trauma (Gentili and Cancedda, 2009). Its biophysical and biochemical properties are also responsible for the adhesion, nutrition, integrity, migration, and differentiation of individual cells (Ostadal et al., 1995).

\section{Extracellular Matrix (ECM)}

Extracellular matrix is a complex macromolecule network that can undergo self-assembly, and serves as both a reservoir for cytokines and growth factors, as well as a scaffold for tissue and cells (Kresse and Schonherr, 2001). Articular cartilage matrix consists of a strong, dense network of collagen fibers ( $60 \%$ dry weight), primarily type II collagen ( $80 \%$ of the total collagen) 
interwoven with proteoglycan (PG) (25-35\% dry weight) and other non-collagenous proteins (15-20\% dry weight) (Azhim et al., 2011). Aggrecan is the largest component of cartilage by percent composition and attracts water molecules, and is responsible for the high shock absorbance of cartilage under load (Gentili and Cancedda, 2009; Maldonado and Nam, 2013).

Extracellular matrix derived from human dermal fibroblasts was found to improve chondrogenesis and stem cell proliferation versus tissue culture plastic (TCP) (Zhou et al., 2016). MSCs-derived ECM (MSC-ECM) was employed as a culture substrate to rejuvenate aged mouse stem cells and enhance their lineage differentiation capacity (Li J. et al., 2014). Porcine synovium-derived stem cell deposited ECM was proven to increase chondrocyte proliferation and delay chondrocyte dedifferentiation (Pei and He, 2012). Cell-derived decellularized extracellular matrix (dECM) has been used as a culture substrate for MSCs to improve cell proliferation and lineagespecific differentiation, and DECM-expanded chondrocytes with enhanced anti-inflammatory properties hold great potential in clinical ACI-based cartilage repair (Yan J. et al., 2020). The chondrocytes seeded onto decellularized human bone marrow derived MSC-ECM (hBMSC-ECM) displayed a significantly greater proliferation rate, maintaining improved chondrocytic phenotype in comparison to the TCP group (Yang Y. et al., 2018). As synovium-derived stem cells (SDSCs) were proposed as tissue-specific stem cells for chondrogenesis, decellularized ECM deposited by SDSCs (SECM) provided an appropriate tissue-specific matrix microenvironment encouraging adult SDSC rejuvenation and improving the regeneration of cartilage (Li et al., 2020).

\section{Decellularized Extracellular Matrix (dECM)}

Using dECM as a scaffold presents several major advantages since the scaffold maintains its original geometry, unlike other processing methods where the $\mathrm{dECM}$ is totally pulverized (Kim Y.S. et al., 2019). Depending on the desired topography, composition, and mechanical properties, dECM can be formed from different types of tissue (Yin et al., 2013). However, to achieve these benefits: (a) the dECM must be thoroughly recellularized and; (b) cell debris must be removed from the tissue without destroying collagen fibers, GAGs, and other essential ECM components (Kim Y.S. et al., 2019). dECMs from cartilage tissues ( $\mathrm{T}$-dECMs) and cartilageforming cells (C-dECMs) can be fabricated using enzymatic, chemical, and/or physical methods (Figure 2) (Sun et al., 2018). Both dECM types possess biocompatibility and are able to support chondrogenesis. Notably, cartilage T-dECMs supported chondrogenic differentiation at a higher likelihood than C-dECMs, which more effectively support proliferation and overall chondrogenic differentiation (Sun et al., 2018).

Cartilage T-dECMs with a 3D interconnected porous environment may contribute toward cell proliferation during chondrogenesis and support cellular infiltration. Hyaline and cartilage T-dECMs, both alone (Chang et al., 2014; Rothrauff et al., 2017) or in conjunction with pro-chondrogenic factors (Yang et al., 2008; Schwarz et al., 2012; Rowland et al., 2016), bolstered in vitro chondrogenesis of reseeded

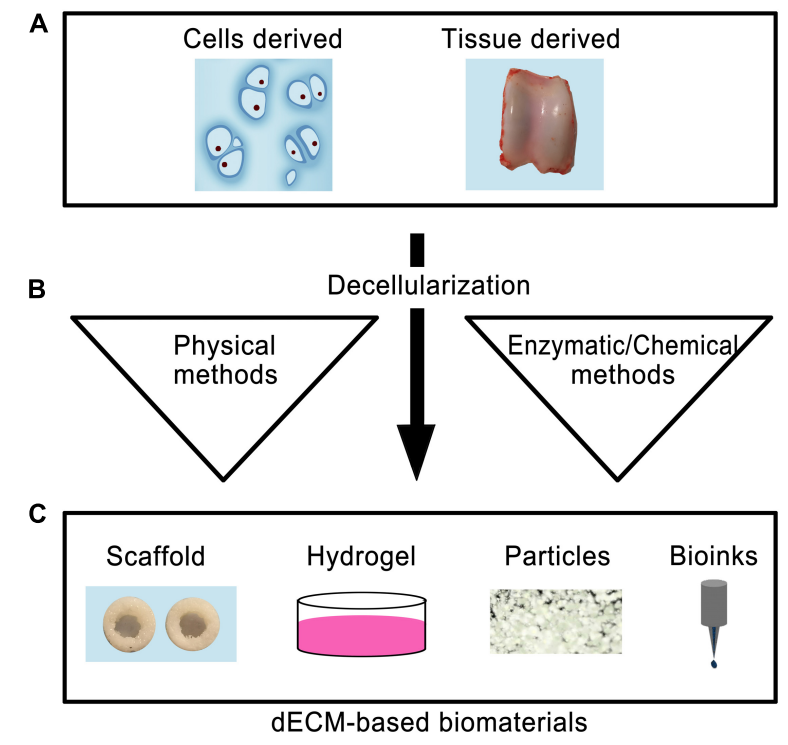

FIGURE 2 | Schematic representation of the use of decellularized biomaterials for cartilage tissue engineering. The cells or tissue-derived biomaterials (A) are subjected to decellarization through physical, enzymatic, or chemical methods (B). The resultant dECM biomaterials can be used to produce scaffold, hydrogel, particle forms, or used as bioinks for 3D printing (C).

chondrocytes/stem cells. When implanted in vivo, they also led to the repair of cartilage defects and formation of cartilage tissues (Yang et al., 2008, 2010; Kang et al., 2014). Surprisingly, new hyaline cartilage formation also occurred following the in vivo implantation of cartilage T-dECMs that had not been supplemented with chondrocytes/stem cells (Grevemeyer et al., 2014; Novak et al., 2016).

\section{Recellularizing dECM}

Scaffolds may increase cartilage regeneration ability if cells are reseeded on decellularized cartilage scaffolds (Xia et al., 2019). Different types of cells have been investigated for cartilage recellularization, including infrapatellar fat pad derived stem cells, bone marrow mesenchymal stem cells (BMSCs), chondrocytes, ASC, and synovium-derived MSCs (Xia et al., 2019). Nonetheless, the decellularization of cartilage and ensuing seeding of cells has proven challenging due to the density of the ECM. Luo et al. (2015) created a channel system in porcine cartilage disks, allowing much improved fluid and cell penetration. Because proteoglycans in cartilage impair cell adhesion (Rich et al., 1981; Yamagata et al., 1989), scientists have also attempted to improve cell adhesion by removing GAGs from cartilage tissue (Elsaesser et al., 2014). For instance, Bautista et al. (2016) incorporated chondroitinase $\mathrm{ABC}$ during decellularization with the intent of removing GAGs from porcine articular cartilage. While successful in enhancing decellularization, the treatment did not improve recellularization rates. Furthermore, dECM scaffolds cannot be readily scaled despite their strengths and ability to sustain a native architecture although highly porous dECM scaffolds with different geometries 
have been produced with methods such as freeze-drying in order to overcome this barrier (Chen et al., 2015; Gawlitta et al., 2015).

\section{Hydrogels (HG)}

Hydrogels (HG) are a class of soft materials comprised of crosslinked polymer chains arranged in a porous 3D network, which are known for their ability to hold up to $99.9 \%$ water by weight. They are fabricated from either synthetic or natural sources and possess good mechanical properties together with unique biocompatibility (Curvello et al., 2019). Several hydrogels have been utilized extensively in recent decades, with varying composition, structures, and properties. HGs have been introduced in medical applications such as biosensors, contact lenses, drug delivery devices, and artificial implant linings (Meng et al., 2019), as well as wound dressings, scaffolds, and hygienic products (Alves et al., 2016; Jung et al., 2017).

Hydrogel scaffolds exhibit compressive strength and allow load transfer from the environment to chondrocytes (Spiller et al., 2011). Hydrogels mimic the physical and chemical conditions of the extracellular matrix, promoting cell differentiation and multiplication along with bolstering integration with trauma sites (Arakaki et al., 2010). Combinatorial hydrogels are a class of hydrogels that allow for the study of cellular responses to multiple biophysical (e.g., crosslink density) and biochemical (e.g., ligand tethering) signals (Benmassaoud et al., 2020).

Natural hydrogel constructs are often composed of polysaccharide or protein chains. Polysaccharides have beneficial hydrophilic structures that enable the creation of hydrogels from many different biomaterials, such as dextran, chitin, alginate, chitosan, cellulose, starch, pectin, xanthan gum, and HA. Synthetic polymers such as polyacrylamide, PVA, PEG, and PEO have all been used for hydrogel formation. While synthetic photopolymerizable hydrogels are cell-compatible, the presence of long-lasting polymer components compromises their mechanical performance and hinders cell migration (Lee et al., 2006; Roberts and Bryant, 2013).

Hydrogels can promote chondrogenic potential and allow for in situ scaffold formation without open surgery. Solutions can be injected intra-articularly without affecting chondrocyte colonization or cartilage differentiation (Li S. et al., 2019). Solid supporters can be added to boost the mechanical stability of hydrogels (Huang et al., 2014). Hydrogels produced with artificial polymers, such as PCL, PLGA, PEG, and polymethyl methacrylate (PMMA), can reach mechanical strengths of 20$120 \mathrm{MPa}$ (Pahlevanzadeh et al., 2018). Polymeric blending of natural and synthetic polymers can produce hydrogels with differing chemical and physical properties for various biomedical applications (Li L. et al., 2019).

\section{FABRICATIONS AND PREPARATION TECHNIQUES OF BIOLOGICAL SCAFFOLDS}

Scaffolds are clinically superior to scaffold-free environments, forgoing invasive surgical procedures for tissue extraction from patients. Additionally, scaffolds provide increased control over the filling of cartilage defects and can reduce patient recovery times (Caron et al., 2012). Cell migration and adhesion are influenced by the microarchitecture and geometry of scaffolds (Oh et al., 2010) as well as pore size. Pores should be small enough to give cells a sufficient surface area for adhesion, yet large enough to enable ECM production and cell migration (Chen et al., 2006). Porous $3 \mathrm{D}$ scaffolds are a prominent option for tissue engineering because they mimic in vivo physiological microenvironments closely. Their excellent porosity also enables cell growth, migration, and adhesion by providing necessary nutrition and transporting metabolic waste (Ma et al., 2018). As a result, the selection of a 3D scaffold is important when determining how the scaffold will behave in different tissue engineering applications (Ko et al., 2010). The differences between scaffold preparation processes have significant influence on the shape, size and porosity of the hole in the support, which may directly affect the migration, differentiation and proliferation of seed cells (Fu et al., 2018). Advances in manufacturing have resulted in 3D printing as a leading technology for producing tunable scaffolds in the field of TE (Cheng A. et al., 2019).

\section{Three-Dimensional (3D) Bioprinting Techniques}

Cartilage is an avascular, alymphatic, and aneural tissue with limited self-renewal, which makes cartilage a relatively simple tissue for regenerating damaged cartilage through bioprinting approaches. Moreover, its organized zonal cell matrix distribution and density makes it suitable for duplication by $3 \mathrm{D}$ bioprinting (Figure 3) (Ji X.F. et al., 2018). Bioprinting offers great prospects of printing tissue analogs through the delivery of live cells with suitable material in a defined and organized manner (Derby, 2012). The concept of bioprinting is essentially an extension of the idea that uses additive manufacturing (AM) methods for building up 3D tissue structures layerby-layer (Kundu et al., 2015), from the bottom up, with high-resolution deposition of materials and cells as well as a customized inner structure, with the aim of duplicating the complexity of native tissues or restoring damaged structure and functionality (Ji X.F. et al., 2018). This advancement has made custom patient-tailored product fabrication possible as MRI and CT images can now be used to create personalized solutions (Roseti et al., 2017).

Three-dimensional bioprinting is a modern method for 3D living tissue/organ structure fabrication using "bioinks" (Buckwalter et al., 2004; Levingstone et al., 2016). A wide range of bioinks have been developed for micro-extrusion and inkjet bioprinting, including agarose, GelMA, alginate, silk, collagen, fibrin, and forms of poly(ethylene) glycol (PEG) and HA (Daly et al., 2017). The two primary bioink categories are scaffoldbased and scaffold-free. Scaffold-based bioinks include cells and biomaterials, creating a scaffold with structural support for cell differentiation and growth (Roseti et al., 2017). Scaffoldfree bioinks are composed of aggregates such as tissue strands, cell pellets, and spheroids that secrete ECM (Gruene et al., 2011). Scaffold-based bioinks are more common, although both types can complement the other's strengths and weaknesses (Ozbolat, 2015). 


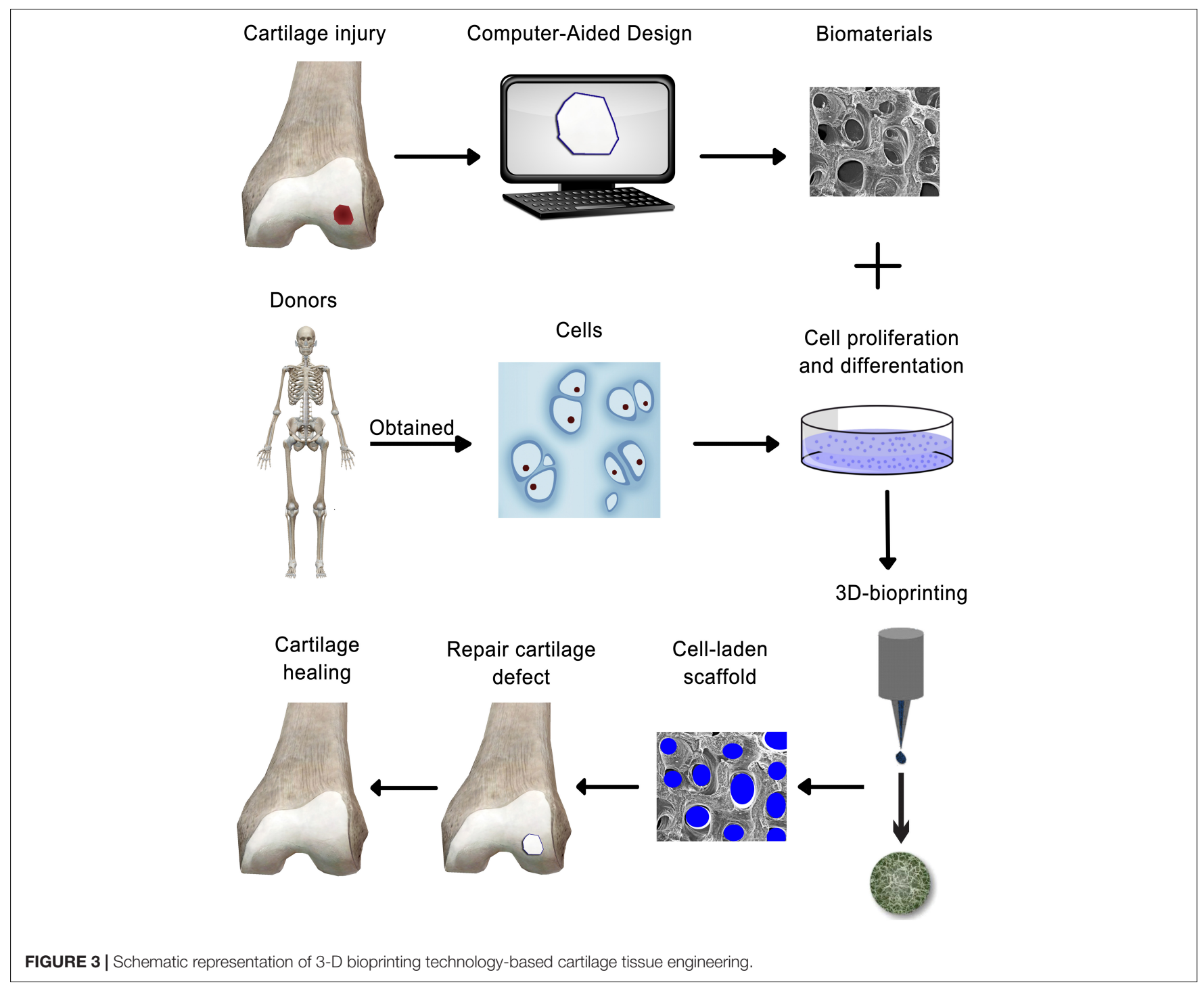

Conventional "subtractive methods" remove materials from an initial block using a top-to-bottom approach, in which cells are seeded onto the finished scaffold at a later time (Bishop et al., 2017; Ngo et al., 2018). Due to the intrinsic nature of bioprinting, finer control over cell spatial distribution can be achieved, producing more homogenous scaffolds that better support cell viability (Roseti et al., 2018).

3D bioprinting typically begins with a computer-assisted design/model for depositing live cells and biomaterials onto a new $3 \mathrm{D}$ biostructure, after which post-processing results in the maturation of these cell-laden constructs (Murphy and Atala, 2014). A chondro-inductive bioink was created by combining alginate, gellan, and cartilage ECM particles (Kesti et al., 2015). The ink was capable of printing highly accurate anatomical shapes, and matrix components were produced successfully (Daly et al., 2017). In a novel scaffold-free bioprinting method, modular cartilage tissue strands generated by fusing tissue spheroids in a confining mold were capable of being printed into 3D constructs using a robotic dispensing system (Yu et al., 2016).
The most prevalent scaffold-based 3D bioprinting technologies today are based on laser technology, extrusion, and jetting (Table 3) (Roseti et al., 2018). Jetting-based 3D bioprinting can be conducted using either a continuous inkjet or using specifically distributed deposition of single droplets (drop-on-demand) (Irvine and Venkatraman, 2016). The drop-on-demand method includes three distinct droplet generation strategies: electrostatic, piezoelectric, and thermal (80-90\%) (Roseti et al., 2018). A novel bioprinting approach was developed to print ovine MSC constructs submerged in oil (Roseti et al., 2018).

Laser-based 3D bioprinting is a complex, expensive technique involving the use of pulsed laser energy to transfer materials to a receiving substrate (Roseti et al., 2018), which can initiate a two-layer droplet release (Dhawan et al., 2019). The top layer comprises an energy absorbing donor layer, whereas the bottom layer is the selected bioink. Bioink droplet release occurs after emission of the laser pulse onto the top donor surface layer, producing a bubble at the interface between the layers and 
TABLE 3 | Comparison of the three types of 3-D bioprinting techniques.

\begin{tabular}{|c|c|c|c|}
\hline & Jetting-based & Extrusion-based & Laser-based \\
\hline Printer cost & Low & Moderate & High \\
\hline Biomaterial viscosity & Medium & High & Medium to high \\
\hline Print speed & Fast (1-10,000 droplets/s) & Slow $(10-50 \mu \mathrm{m} / \mathrm{s})$ & Medium-fast (200-1,600 mm/s) \\
\hline Cell viability (\%) & $80 \%-90 \%$ & $40 \%-95 \%$ & $95 \%$ \\
\hline Resolution & High (up to $50 \mu \mathrm{m}$ ) & Moderate (100 $\mu \mathrm{m}$ to millimeters) & High $(10-50 \mu \mathrm{m})$ \\
\hline Cell densities & Low ( $\leq 106$ cells/ml) & High (cell spheroids) & Medium ( $\leq 108$ cells/ml) \\
\hline $\begin{array}{l}\text { Quality of vertical } \\
\text { structure }\end{array}$ & Poor & Good & Fair \\
\hline Advantage & $\begin{array}{l}\text { High cell viability; } \\
\text { High printing speeds; } \\
\text { Low cost; } \\
\text { Wide availability; } \\
\text { Easy operation }\end{array}$ & $\begin{array}{l}\text { High cell densities; } \\
\text { High cell viability; } \\
\text { Broad selection of biomaterials; } \\
\text { High deposition rates; } \\
\text { High print speeds; } \\
\text { Anatomically correct porous construct } \\
\text { generation }\end{array}$ & $\begin{array}{l}\text { Nozzle free; } \\
\text { Fast and accurate fabrication; } \\
\text { High resolution; } \\
\text { High precision; } \\
\text { High cell viabilities }\end{array}$ \\
\hline Disadvantage & $\begin{array}{l}\text { Low droplet directionality; } \\
\text { Nozzle clogging; } \\
\text { Limited biomaterials selection; } \\
\text { Low cell density and concentration of the } \\
\text { ink; } \\
\text { Heat and sheer stresses induced damage } \\
\text { to cells }\end{array}$ & $\begin{array}{l}\text { Low resolution; } \\
\text { Deformation; } \\
\text { Encapsulated cell apoptosis; } \\
\text { Low cell viability }\end{array}$ & $\begin{array}{l}\text { High cost; } \\
\text { Low speed; } \\
\text { Low built capability; } \\
\text { Possible cytotoxicity; } \\
\text { UV induced DNA damage; } \\
\text { Low stability and scalability; } \\
\text { Limited printing directionality }\end{array}$ \\
\hline $\begin{array}{l}\text { Tissue engineering } \\
\text { application }\end{array}$ & Blood vessel, bone, cartilage, neuron, liver & $\begin{array}{l}\text { Blood vessel, bone, lungs, liver, } \\
\text { cartilage, neuron, muscle, ear, skin, lipid } \\
\text { bilayers }\end{array}$ & $\begin{array}{l}\text { Blood vessel, bone, skin, adipose, cardiac } \\
\text { tissue }\end{array}$ \\
\hline References & $\begin{array}{l}\text { Irvine and Venkatraman (2016), Roseti et al. } \\
\text { (2018), Roseti et al. (2017) }\end{array}$ & $\begin{array}{l}\text { Cole et al. (2009), Hasan et al. (2014), } \\
\text { Daly et al. (2016), Pillai et al. (2018), } \\
\text { Dhawan et al. (2019) }\end{array}$ & $\begin{array}{l}\text { Roseti et al. (2018), Dhawan et al. (2019), } \\
\text { Irvine and Venkatraman (2016) }\end{array}$ \\
\hline
\end{tabular}

propelling the droplet onto the substrate (Dhawan et al., 2019). This method avoids mechanical stress from direct contact with the printer and has greater resolution and precision than other options. The biggest obstacle is the cost of laser-based systems (Dhawan et al., 2019). The size and complexity of the required equipment also limits its usage, along with its inferior cell viability relative to inkjet mechanisms (Irvine and Venkatraman, 2016).

Extrusion-based bioprinting is a pressure-based bioprinting method currently employed in the fabrication of heterogenous scaffolds for osteochondral regeneration (Dhawan et al., 2019). This technology is the basis for most commercial bioprinters, and uses a micro-nozzle to dispense bioink filaments via pneumatic or piston pressure. This system is run by mechanical, solenoid, or pneumatic control. A wide variety of bioinks, such as tissue spheroids, hydrogels, tissue stands, and microcarriers, can be used due to the large, flexible nozzle size. This technique has been applied successfully to print several types of tissues, such as lungs, cartilage, liver tissue, and lipid bilayers (Hasan et al., 2014; Pillai et al., 2018). This technique can release highly viscous bioinks with the micro-nozzle, raising deposition rates and printing speed and enabling the use of synthetic polymers (Dhawan et al., 2019). Other strengths include production scalability, high cell viability, and anatomically correct porous construct generation (Dhawan et al., 2019). However, high pressure associated with mechanical extrusion poses drawbacks such as low resolution, deformation, and encapsulated cell apoptosis (Cole et al., 2009; Daly et al., 2016). Nonetheless, the mechanical qualities of bioprinted constructs are subpar compared to those of the native tissue and require further optimizations.

\section{CONCLUSION AND FUTURE DIRECTIONS}

Effective repairing of damaged cartilage tissues caused by high impact sports or diseases remain a major clinical challenge. CTE provides a promising avenue to this unmet challenge. Significant progresses have been made in CTE, including the identification and the use of chondrogenic biofactors, the isolation and characterization of chondrogenic progenitors from various sources, and the development of cell-friendly, biocompatible scaffold materials. The rapid advance of 3Dbioprinting techniques further facilitates the clinical realization of CTE. Nonetheless, many hurdles remain ahead of successful and effective CTE. At the basic research front, we need a better understanding of cartilage biology, including the layered/zoned structures with different organization, and the distinct morphologies and functionalities of chondrocytes in different layers/zones. Efforts have to be devoted to the characterization and optimization of efficacious chondrogenic biofactors. Another challenge is to establish reliable techniques to generate sufficient chondrogenic progenitor cells from various cell sources, including MSCs from different tissues or effectively directed chondrogenic differentiation from iPSCs. As discussed above, many biocompatible scaffold biomaterials 
have been developed; but vast majority need to be rigorously tested in pre-clinical studies and clinical trials. Ultimately, a 3D-bioprinting fabrication may offer the opportunity to assemble chondrogenic factor-stimulated and progenitor cellloaded scaffold biomaterials to accomplish effective regeneration and repair of injured cartilage.

\section{AUTHOR CONTRIBUTIONS}

All authors contributed to the article and approved the submitted version.

\section{FUNDING}

The reported work was supported in part by a research grant from the National Institutes of Health (CA226303 to

\section{REFERENCES}

Ahmed, T. A., and Hincke, M. T. (2010). Strategies for articular cartilage lesion repair and functional restoration. Tissue Eng. Part B Rev. 16, 305-329. doi: 10.1089/ten.TEB.2009.0590

Ahmed, T. A., and Hincke, M. T. (2014). Mesenchymal stem cell-based tissue engineering strategies for repair of articular cartilage. Histol. Histopathol. 29, 669-689. doi: 10.14670/HH-29.669

Akeda, K., An, H. S., Okuma, M., Attawia, M., Miyamoto, K., Thonar, E. J., et al. (2006). Platelet-rich plasma stimulates porcine articular chondrocyte proliferation and matrix biosynthesis. Osteoarthritis Cartilage 14, 1272-1280. doi: 10.1016/j.joca.2006.05.008

Aldana, A. A., and Abraham, G. A. (2017). Current advances in electrospun gelatinbased scaffolds for tissue engineering applications. Int. J. Pharm. 523, 441-453. doi: 10.1016/j.ijpharm.2016.09.044

Alkaya, D., Gurcan, C., Kilic, P., Yilmazer, A., and Gurman, G. (2020). Where is human-based cellular pharmaceutical R\&D taking us in cartilage regeneration? 3 Biotech 10:161. doi: 10.1007/s13205-020-2134-2135

Altman, G. H., Horan, R. L., Lu, H. H., Moreau, J., Martin, I., Richmond, J. C., et al. (2002). Silk matrix for tissue engineered anterior cruciate ligaments. Biomaterials 23, 4131-4141. doi: 10.1016/s0142-9612(02)00156-154

Alves, D. A., Machado, D., Melo, A., Pereira, R. F., Severino, P., de Hollanda, L. M., et al. (2016). Preparation of thermosensitive gel for controlled release of levofloxacin and their application in the treatment of multidrug-resistant bacteria. Biomed. Res. Int. 2016:9702129. doi: 10.1155/2016/9702129

Arakaki, K., Kitamura, N., Fujiki, H., Kurokawa, T., Iwamoto, M., Ueno, M., et al. (2010). Artificial cartilage made from a novel double-network hydrogel: in vivo effects on the normal cartilage and ex vivo evaluation of the friction property. J. Biomed. Mater. Res. A 93, 1160-1168. doi: 10.1002/jbm.a.32613

Arlov, O., Aachmann, F. L., Sundan, A., Espevik, T., and Skjak-Braek, G. (2014). Heparin-like properties of sulfated alginates with defined sequences and sulfation degrees. Biomacromolecules 15, 2744-2750. doi: 10.1021/bm500602w

Athanasiou, K. A., Niederauer, G. G., and Agrawal, C. M. (1996). Sterilization, toxicity, biocompatibility and clinical applications of polylactic acid polyglycolic acid copolymers. Biomaterials 17, 93-102. doi: 10.1016/0142-9612(96)85754-85751

Azhim, A., Yamagami, K., Muramatsu, K., Morimoto, Y., and Tanaka, M. (2011). The use of sonication treatment to completely decellularize blood arteries: a pilot study. Annu. Int. Conf. IEEE Eng. Med. Biol. Soc. 2011, 2468-2471.

Barbon, S., Stocco, E., Macchi, V., Contran, M., Grandi, F., Borean, A., et al. (2019). Platelet-Rich fibrin scaffolds for cartilage and tendon regenerative medicine: from bench to bedside. Int. J. Mol. Sci. 20:1701. doi: 10.3390/ijms20071701

Bautista, C. A., Park, H. J., Mazur, C. M., Aaron, R. K., and Bilgen, B. (2016). Effects of chondroitinase $\mathrm{ABC}-$ Mediated proteoglycan digestion on decellularization and recellularization of articular cartilage. PLoS One 11:e0158976. doi: 10.1371/ journal.pone. 0158976
T-CH). WW was supported by the Medical Scientist Training Program of the National Institutes of Health (T32 GM007281). This project was also supported in part by The University of Chicago Cancer Center Support Grant (P30CA014599) and the National Center for Advancing Translational Sciences (NCATS) of the National Institutes of Health (NIH) through Grant Number 5UL1TR002389-02 that funds the Institute for Translational Medicine (ITM) although the contents are solely the responsibility of the authors and do not necessarily represent the official views of the NIH. SH and T-CH were supported by the SHOCK Fund at The University of Chicago, and T-CH was also supported by the Mabel Green Myers Research Endowment Fund and The University of Chicago Orthopaedics Alumni Fund. Funding sources were not involved in the study design; in the collection, analysis and interpretation of data; in the writing of the report; and in the decision to submit the manuscript for publication.

Beederman, M., Lamplot, J. D., Nan, G., Wang, J., Liu, X., Yin, L., et al. (2013). BMP signaling in mesenchymal stem cell differentiation and bone formation. J. Biomed. Sci. Eng. 6, 32-52. doi: 10.4236/jbise.2013.68A1004

Benmassaoud, M. M., Gultian, K. A., DiCerbo, M., and Vega, S. L. (2020). Hydrogel screening approaches for bone and cartilage tissue regeneration. Ann. N. Y. Acad. Sci. 1460, 25-42. doi: 10.1111/nyas. 14247

Bentley, G., Biant, L. C., Carrington, R. W., Akmal, M., Goldberg, A., Williams, A. M., et al. (2003). A prospective, randomised comparison of autologous chondrocyte implantation versus mosaicplasty for osteochondral defects in the knee. J. Bone Joint Surg. Br. 85, 223-230. doi: 10.1302/0301-620x.85b2. 13543

Bharadwaz, A., and Jayasuriya, A. C. (2020). Recent trends in the application of widely used natural and synthetic polymer nanocomposites in bone tissue regeneration. Mater. Sci. Eng. C Mater. Biol. Appl. 110:110698. doi: 10.1016/j. msec.2020.110698

Bhattacharjee, P., Naskar, D., Maiti, T. K., Bhattacharya, D., Das, P., Nandi, S. K., et al. (2016). Potential of non-mulberry silk protein fibroin blended and grafted poly(capital JE, Ukrainian-caprolactone) nanofibrous matrices for in vivo bone regeneration. Colloids Surf. B Biointerfaces 143, 431-439. doi: 10.1016/j.colsurfb.2016.03.058

Bian, L., Zhai, D. Y., Tous, E., Rai, R., Mauck, R. L., and Burdick, J. A. (2011). Enhanced MSC chondrogenesis following delivery of TGF-beta3 from alginate microspheres within hyaluronic acid hydrogels in vitro and in vivo. Biomaterials 32, 6425-6434. doi: 10.1016/j.biomaterials.2011.05.033

Birru, B., Mekala, N. K., and Parcha, S. R. (2018). Improved osteogenic differentiation of umbilical cord blood MSCs using custom made perfusion bioreactor. Biomed. J. 41, 290-297. doi: 10.1016/j.bj.2018.07.002

Bishop, E. S., Mostafa, S., Pakvasa, M., Luu, H. H., Lee, M. J., Wolf, J. M., et al. (2017). 3-D bioprinting technologies in tissue engineering and regenerative medicine: current and future trends. Genes Dis. 4, 185-195. doi: 10.1016/j. gendis.2017.10.002

Bouhadir, K. H., Lee, K. Y., Alsberg, E., Damm, K. L., Anderson, K. W., and Mooney, D. J. (2001). Degradation of partially oxidized alginate and its potential application for tissue engineering. Biotechnol. Prog. 17, 945-950. doi: 10.1021/ bp010070p

Brandl, A., Angele, P., Roll, C., Prantl, L., Kujat, R., and Kinner, B. (2010). Influence of the growth factors PDGF-BB, TGF-betal and bFGF on the replicative aging of human articular chondrocytes during in vitro expansion. J. Orthop. Res. 28, 354-360. doi: 10.1002/jor.21007

Buckwalter, J. A., Saltzman, C., and Brown, T. (2004). The impact of osteoarthritis: implications for research. Clin. Orthop. Relat. Res. 427(Suppl.), S6-S15. doi: 10.1097/01.blo.0000143938.30681.9d

Burnouf, T., Lee, C. Y., Luo, C. W., Kuo, Y. P., Chou, M. L., Wu, Y. W., et al. (2012). Human blood-derived fibrin releasates: composition and use for the culture of cell lines and human primary cells. Biologicals 40, 21-30. doi: 10.1016/ j.biologicals.2011.09.017 
Caloprisco, G., and Borean, A. (2011). Leucocyte-Platelet haemocomponents for topical use: regenerative potentiality. Adv. Minimally Invasive Surg. Therapy Spine Nerves 108, 209-211. doi: 10.1007/978-3-211-99370-5_32

Caloprisco, G., Borean, A., De Angeli, S., Gaio, G. B., Boito, K., Del Pup, L., et al. (2010). New method to produce hemocomponents for regenerative use from peripheral blood: integration among platelet growth factors monocytes and stem cells. Transfus. Apheresis Sci. 42, 117-124. doi: 10.1016/j.transci.2010. 01.003

Camarero-Espinosa, S., Rothen-Rutishauser, B., Foster, E. J., and Weder, C. (2016). Articular cartilage: from formation to tissue engineering. Biomater. Sci. 4, 734-767. doi: 10.1039/c6bm00068a

Cao, J. J., Singleton, P. A., Majumdar, S., Boudignon, B., Burghardt, A., Kurimoto, P., et al. (2005). Hyaluronan increases RANKL expression in bone marrow stromal cells through CD44. J. Bone Miner. Res. 20, 30-40. doi: 10.1359/JBMR. 041014

Caron, M. M., Emans, P. J., Coolsen, M. M., Voss, L., Surtel, D. A., Cremers, A., et al. (2012). Redifferentiation of dedifferentiated human articular chondrocytes: comparison of 2D and 3D cultures. Osteoarthritis Cartilage 20, 1170-1178. doi: 10.1016/j.joca.2012.06.016

Castro-Vinuelas, R., Sanjurjo-Rodriguez, C., Pineiro-Ramil, M., Hermida-Gomez, T., Fuentes-Boquete, I. M., de Toro-Santos, F. J., et al. (2018). Induced pluripotent stem cells for cartilage repair: current status and future perspectives. Eur. Cell Mater. 36, 96-109. doi: 10.22203/eCM.v036a08

Chang, C. H., Chen, C. C., Liao, C. H., Lin, F. H., Hsu, Y. M., and Fang, H. W. (2014). Human acellular cartilage matrix powders as a biological scaffold for cartilage tissue engineering with synovium-derived mesenchymal stem cells. J. Biomed. Mater. Res. Part A 102, 2248-2257. doi: 10.1002/jbm.a.34897

Chen, D., Shen, J., Zhao, W., Wang, T., Han, L., Hamilton, J. L., et al. (2017). Osteoarthritis: toward a comprehensive understanding of pathological mechanism. Bone Res. 5:16044. doi: 10.1038/boneres.2016.44

Chen, F. H., Rousche, K. T., and Tuan, R. S. (2006). Technology Insight: adult stem cells in cartilage regeneration and tissue engineering. Nat. Clin. Pract. Rheumatol. 2, 373-382. doi: 10.1038/ncprheum0216

Chen, M., Xu, L., Zhou, Y., Zhang, Y., Lang, M., Ye, Z., et al. (2016). Poly(epsiloncaprolactone)-based substrates bearing pendant small chemical groups as a platform for systemic investigation of chondrogenesis. Cell Prolif. 49, 512-522. doi: $10.1111 /$ cpr. 12272

Chen, Y. C., Chen, R. N., Jhan, H. J., Liu, D. Z., Ho, H. O., Mao, Y., et al. (2015). Development and characterization of acellular extracellular matrix scaffolds from porcine menisci for use in cartilage tissue engineering. Tissue Eng. Part C-Methods 21, 971-986. doi: 10.1089/ten.tec.2015.0036

Cheng, A., Schwartz, Z., Kahn, A., Li, X., Shao, Z., Sun, M., et al. (2019). Advances in porous scaffold design for bone and cartilage tissue engineering and regeneration. Tissue Eng. Part B Rev. 25, 14-29. doi: 10.1089/ten.TEB.2018.0119

Cheng, H., Fan, X., Wu, C., Wang, X., Wang, L. J., Loh, X. J., et al. (2019). Cyclodextrin-Based star-like amphiphilic cationic polymer as a potential pharmaceutical carrier in macrophages. Macromol. Rapid. Commun. 40:e1800207. doi: 10.1002/marc.201800207

Cheng, H., Fan, X., Wang, X., Ye, E., Loh, X. J., Li, Z., et al. (2018). Hierarchically self-assembled supramolecular host-guest delivery system for drug resistant cancer therapy. Biomacromolecules 19, 1926-1938. doi: 10.1021/acs.biomac. $7 \mathrm{~b} 01693$

Chien, C. S., Ho, H. O., Liang, Y. C., Ko, P. H., Sheu, M. T., and Chen, C. H. (2012). Incorporation of exudates of human platelet-rich fibrin gel in biodegradable fibrin scaffolds for tissue engineering of cartilage. J. Biomed. Mater. Res. B Appl. Biomater. 100, 948-955. doi: 10.1002/jbm.b.32657

Cho, S. H., Lim, S. M., Han, D. K., Yuk, S. H., Il, Im, G., et al. (2009). TimeDependent alginate/polyvinyl alcohol hydrogels as injectable cell carriers. J. Biomater. Sci. Pol. Ed. 20, 863-876. doi: 10.1163/156856209x444312

Chung, C., and Burdick, J. A. (2008). Engineering cartilage tissue. Adv. Drug Deliv. Rev. 60, 243-262. doi: 10.1016/j.addr.2007.08.027

Coalson, E., Bishop, E., Liu, W., Feng, Y., Spezia, M., Liu, B., et al. (2019). Stem cell therapy for chronic skin wounds in the era of personalized medicine: from bench to bedside. Genes Dis. 6, 342-358. doi: 10.1016/j.gendis.2019.09.008

Cole, B. J., Pascual-Garrido, C., and Grumet, R. C. (2009). Surgical management of articular cartilage defects in the knee. J. Bone Joint Surg. Am. 91, 1778-1790.

Collins, M. N., and Birkinshaw, C. (2013). Hyaluronic acid based scaffolds for tissue engineering-a review. Carbohydr. Polym. 92, 1262-1279. doi: 10.1016/j.carbpol. 2012.10.028
Coppola, B., Cappetti, N., Di Maio, L., Scarfato, P., and Incarnato, L. (2018). 3D Printing of PLA/clay nanocomposites: influence of printing temperature on printed samples properties. Materials (Basel) 11:1947. doi: 10.3390/ ma11101947

Curvello, R., Raghuwanshi, V. S., and Garnier, G. (2019). Engineering nanocellulose hydrogels for biomedical applications. Adv. Colloid Interface Sci. 267, 47-61. doi: 10.1016/j.cis.2019.03.002

Daly, A. C., Critchley, S. E., Rencsok, E. M., and Kelly, D. J. (2016). A comparison of different bioinks for 3D bioprinting of fibrocartilage and hyaline cartilage. Biofabrication 8:045002. doi: 10.1088/1758-5090/8/4/045002

Daly, A. C., Freeman, F. E., Gonzalez-Fernandez, T., Critchley, S. E., Nulty, J., and Kelly, D. J. (2017). 3D bioprinting for cartilage and osteochondral tissue engineering. Adv. Healthc. Mater. 6:1700298. doi: 10.1002/adhm.20170 0298

Datta, A., Ghosh, A. K., and Kundu, S. C. (2001). Purification and characterization of fibroin from the tropical saturniid silkworm. antheraea mylitta. Insect. Biochem. Mol. Biol. 31, 1013-1018. doi: 10.1016/s0965-1748(01)00049-42

Deng, D., Liu, W., Xu, F., Yang, Y., Zhou, G., Zhang, W. J., et al. (2009). Engineering human neo-tendon tissue in vitro with human dermal fibroblasts under static mechanical strain. Biomaterials 30, 6724-6730. doi: 10.1016/j.biomaterials. 2009.08.054

Derby, B. (2012). Printing and prototyping of tissues and scaffolds. Science 338, 921-926. doi: 10.1126/science. 1226340

Dhawan, A., Kennedy, P. M., Rizk, E. B., and Ozbolat, I. T. (2019). Threedimensional bioprinting for bone and cartilage restoration in orthopaedic surgery. J. Am. Acad. Orthop. Surg. 27, e215-e226. doi: 10.5435/JAAOS-D-1700632

Di Liddo, R., Bertalot, T., Borean, A., Pirola, I., Argentoni, A., Schrenk, S., et al. (2018). Leucocyte and platelet-rich fibrin: a carrier of autologous multipotent cells for regenerative medicine. J. Cell Mol. Med. 22, 1840-1854. doi: 10.1111/ jcmm. 13468

Diduch, D. R., Jordan, L. C., Mierisch, C. M., and Balian, G. (2000). Marrow stromal cells embedded in alginate for repair of osteochondral defects. Arthroscopy 16, 571-577. doi: 10.1053/jars.2000.4827

Ding, C., and Li, Z. (2017). A review of drug release mechanisms from nanocarrier systems. Mater. Sci. Eng. C Mater. Biol. Appl. 76, 1440-1453. doi: 10.1016/j. msec.2017.03.130

Dizon, J. R. C., Espera, A. H., Chen, Q. Y., and Advincula, R. C. (2018). O Mechanical characterization of 3D-printed polymers. Add. Manufact. 20, 4467. doi: 10.1016/j.addma.2017.12.002

Dohan, D. M., Choukroun, J., Diss, A., Dohan, S. L., Dohan, A. J., Mouhyi, J., et al. (2006). Platelet-rich fibrin (PRF): a second-generation platelet concentrate. Part III: leucocyte activation: a new feature for platelet concentrates? Oral. Surg. Oral. Med. Oral. Pathol. Oral. Radiol. Endod. 101, e51-e55. doi: 10.1016/j. tripleo.2005.07.010

Domingos, M., Chiellini, F., Gloria, A., Ambrosio, L., Bartolo, P., and Chiellini, E. (2012). Effect of process parameters on the morphological and mechanical properties of 3D Bioextruded poly( $\varepsilon$-caprolactone) scaffolds. Rapid Prototyping J. 18, 56-67. doi: 10.1108/13552541211193502

Du, N., Yang, Z., Liu, X. Y., Li, Y., and Xu, H. Y. (2011). Structural origin of the strain-hardening of spider silk. Adv. Funct. Mater. 21, 772-778. doi: 10.1002/ adfm.201001397

Dutta, S. D., Patel, D. K., and Lim, K. T. (2019). Functional cellulose-based hydrogels as extracellular matrices for tissue engineering. J. Biol. Eng. 13:55. doi: 10.1186/s13036-019-0177-170

Echave, M. C., Hernaez-Moya, R., Iturriaga, L., Pedraz, J. L., Lakshminarayanan, R., Dolatshahi-Pirouz, A., et al. (2019). Recent advances in gelatin-based therapeutics. Expert Opin. Biol. Ther. 19, 773-779. doi: 10.1080/14712598.2019. 1610383

Edward Semple, J., Sullivan, B., Vojkovsky, T., and Sill, K. N. (2016). Synthesis and facile end-group quantification of functionalized PEG azides. J. Polym. Sci. A Polym. Chem. 54, 2888-2895. doi: 10.1002/pola.28174

Eichhorn, S. J., Young, R. J., and Davies, G. R. (2005). Modeling crystal and molecular deformation in regenerated cellulose fibers. Biomacromolecules 6 , 507-513. doi: 10.1021/bm049409x

Elsaesser, A. F., Bermueller, C., Schwarz, S., Koerber, L., Breiter, R., and Rotter, N. (2014). In vitro cytotoxicity and in vivo effects of a decellularized xenogeneic collagen scaffold in nasal cartilage repair. Tissue Eng. Part A 20, 1668-1678. doi: 10.1089/ten.TEA.2013.0365 
Erggelet, C., Endres, M., Neumann, K., Morawietz, L., Ringe, J., Haberstroh, K., et al. (2009). Formation of cartilage repair tissue in articular cartilage defects pretreated with microfracture and covered with cell-free polymer-based implants. J. Orthop. Res. 27, 1353-1360. doi: 10.1002/jor.20879

Filardo, G., Perdisa, F., Gelinsky, M., Despang, F., Fini, M., Marcacci, M., et al. (2018). Novel alginate biphasic scaffold for osteochondral regeneration: an in vivo evaluation in rabbit and sheep models. J. Mater. Sci. Mater. Med. 29:74. doi: 10.1007/s10856-018-6074-6070

Fioravanti, C., Frustaci, I., Armellin, E., Condo, R., Arcuri, C., and Cerroni, L. (2015). Autologous blood preparations rich in platelets, fibrin and growth factors. Oral. Implantol. (Rome) 8, 96-113. doi: 10.11138/orl/2015.8.4.096

Fortier, L. A., Barker, J. U., Strauss, E. J., McCarrel, T. M., and Cole, B. J. (2011). The role of growth factors in cartilage repair. Clin. Orthop. Relat. Res. 469, 2706-2715. doi: 10.1007/s11999-011-1857-1853

Freedman, B. R., and Mooney, D. J. (2019). Biomaterials to mimic and heal connective tissues. Adv. Mater. 31:e1806695. doi: 10.1002/adma.201806695

Fu, N., Dong, T., Meng, A., Meng, Z., Zhu, B., and Lin, Y. (2018). Research progress of the types and preparation techniques of scaffold materials in cartilage tissue engineering. Curr. Stem Cell Res. Ther. 13, 583-590. doi: 10. 2174/1574888X12666170718152611

Fu, N., Liao, J., Lin, S., Sun, K., Tian, T., Zhu, B., et al. (2016). PCL-PEG-PCL film promotes cartilage regeneration in vivo. Cell Prolif. 49, 729-739. doi: 10.1111/ cpr.12295

Gaissmaier, C., Koh, J. L., and Weise, K. (2008). Growth and differentiation factors for cartilage healing and repair. Injury 39(Suppl. 1), S88-S96. doi: 10.1016/j. injury.2008.01.035

Gawlitta, D., Benders, K. E. M., Visser, J., van der Sar, A. S., Kempen, D. H. R., Theyse, L. F. H., et al. (2015). Decellularized cartilage-derived matrix as substrate for endochondral bone regeneration. Tissue Eng. Part A 21, 694-703. doi: 10.1089/ten.tea.2014.0117

Ge, Z., Li, C., Heng, B. C., Cao, G., and Yang, Z. (2012). Functional biomaterials for cartilage regeneration. J. Biomed. Mater. Res. A 100, 2526-2536. doi: 10.1002/ jbm.a.34147

Gellynck, K., Verdonk, P. C., Van Nimmen, E., Almqvist, K. F., Gheysens, T., Schoukens, G., et al. (2008). Silkworm and spider silk scaffolds for chondrocyte support. J. Mater. Sci. Mater. Med. 19, 3399-3409. doi: 10.1007/s10856-0083474-3476

Gentili, C., and Cancedda, R. (2009). Cartilage and bone extracellular matrix. Curr. Pharm. Des. 15, 1334-1348. doi: 10.2174/138161209787846739

Giesa, T., Arslan, M., Pugno, N. M., and Buehler, M. J. (2011). Nanoconfinement of spider silk fibrils begets superior strength, extensibility, and toughness. Nano Lett. 11, 5038-5046. doi: 10.1021/nl203108t

Giuliani, C. (2019). The flavonoid quercetin induces AP-1 activation in FRTL-5 Thyroid Cells. Antioxidants (Basel) 8:112. doi: 10.3390/antiox8050112

Gomez-Salazar, M., Gonzalez-Galofre, Z. N., Casamitjana, J., Crisan, M., James, A. W., and Peault, B. (2020). Five decades later, are mesenchymal stem cells still relevant? Front. Bioeng. Biotechnol. 8:148. doi: 10.3389/fbioe.2020.00148

Gonzalez, M. A., Gonzalez-Rey, E., Rico, L., Buscher, D., and Delgado, M. (2009). Treatment of experimental arthritis by inducing immune tolerance with human adipose-derived mesenchymal stem cells. Arthritis Rheum. 60, 1006-1019. doi: 10.1002/art.24405

Gorgieva, S., and Trcek, J. (2019). Bacterial cellulose: production, modification and perspectives in biomedical applications. Nanomaterials (Basel) 9:1352. doi: 10.3390/nano9101352

Gosset, M., Berenbaum, F., Thirion, S., and Jacques, C. (2008). Primary culture and phenotyping of murine chondrocytes. Nat. Protoc. 3, 1253-1260. doi: 10.1038/ nprot.2008.95

Gravert, D. J., and Janda, K. D. (1997). Organic synthesis on soluble polymer supports: liquid-phase methodologies. Chem. Rev. 97, 489-510. doi: 10.1021/ cr960064l

Grecu, A. F., Reclaru, L., Ardelean, L. C., Nica, O., Ciuca, E. M., and Ciurea, M. E. (2019). Platelet-Rich fibrin and its emerging therapeutic benefits for musculoskeletal injury treatment. Medicina (Kaunas) 55:141. doi: 10.3390/ medicina55050141

Green, J. D., Tollemar, V., Dougherty, M., Yan, Z., Yin, L., Ye, J., et al. (2015). Multifaceted signaling regulators of chondrogenesis: implications in cartilage regeneration and tissue engineering. Genes Dis. 2, 307-327. doi: 10.1016/j. gendis.2015.09.003
Grevemeyer, B., Bogdanovic, L., Canton, S., St Jean, G., Cercone, M., Ducharme, N. G., et al. (2014). Regenerative medicine approach to reconstruction of the equine upper airway. Tissue Eng. Part A 20, 1213-1221. doi: 10.1089/ten.TEA. 2013.0217

Gruene, M., Deiwick, A., Koch, L., Schlie, S., Unger, C., Hofmann, N., et al. (2011). Laser printing of stem cells for biofabrication of scaffold-free autologous grafts. Tissue Eng. Part C Methods 17, 79-87. doi: 10.1089/ten.TEC.2010. 0359

Grzesiak, J., Marycz, K., Szarek, D., Bednarz, P., and Laska, J. (2015). Polyurethane/polylactide-based biomaterials combined with rat olfactory bulbderived glial cells and adipose-derived mesenchymal stromal cells for neural regenerative medicine applications. Mater. Sci. Eng. C Mater. Biol. Appl. 52, 163-170. doi: 10.1016/j.msec.2015.03.050

Gupta, R. C., Lall, R., Srivastava, A., and Sinha, A. (2019). Hyaluronic acid: molecular mechanisms and therapeutic trajectory. Front. Vet. Sci. 6:192. doi: 10.3389/fvets.2019.00192

Hasan, J., Fisher, J., and Ingham, E. (2014). Current strategies in meniscal regeneration. J. Biomed. Mater. Res. B Appl. Biomater. 102, 619-634. doi: 10. 1002/jbm.b.33030

Henderson, I., Tuy, B., and Oakes, B. (2004). Reoperation after autologous chondrocyte implantation. Indications and findings. J. Bone Joint Surg. Br. 86, 205-211. doi: 10.1302/0301-620x.86b2.14324

Hoemann, C. D., Sun, J., Legare, A., McKee, M. D., and Buschmann, M. D. (2005). Tissue engineering of cartilage using an injectable and adhesive chitosan-based cell-delivery vehicle. Osteoarthritis Cartilage 13, 318-329. doi: 10.1016/j.joca. 2004.12.001

Hoshikawa, A., Nakayama, Y., Matsuda, T., Oda, H., Nakamura, K., and Mabuchi, K. (2006). Encapsulation of chondrocytes in photopolymerizable styrenated gelatin for cartilage tissue engineering. Tissue Eng. 12, 2333-2341. doi: 10.1089/ ten.2006.12.2333

Huang, H., Zhang, X., Hu, X., Dai, L., Zhu, J., Man, Z., et al. (2014). Directing chondrogenic differentiation of mesenchymal stem cells with a solid-supported chitosan thermogel for cartilage tissue engineering. Biomed. Mater. 9:035008. doi: 10.1088/1748-6041/9/3/035008

Huang, Y., Seitz, D., Konig, F., Muller, P. E., Jansson, V., and Klar, R. M. (2019). Induction of articular chondrogenesis by chitosan/hyaluronic-acidbased biomimetic matrices using human adipose-derived stem cells. Int. J. Mol. Sci. 20:4487. doi: 10.3390/ijms20184487

Hubbe, M. A., Tayeb, P., Joyce, M., Tyagi, P., Kehoe, M., Dimic-Misic, K., et al. (2017). Rheology of nanocellulose-rich aqueous suspensions: a review. Bioresources 12, 9556-9661.

Hunziker, E. B. (2002). Articular cartilage repair: basic science and clinical progress. a review of the current status and prospects. Osteoarthritis Cartilage 10, 432-463. doi: 10.1053/joca.2002.0801

Ibusuki, S., Fujii, Y., Iwamoto, Y., and Matsuda, T. (2003). Tissue-engineered cartilage using an injectable and in situ gelable thermoresponsive gelatin: fabrication and in vitro performance. Tissue Eng. 9, 371-384. doi: 10.1089/ 107632703764664846

Im, G. I. (2020). Biomaterials in orthopaedics: the past and future with immune modulation. Biomater. Res. 24:7. doi: 10.1186/s40824-020-0185-187

Irvine, S. A., and Venkatraman, S. S. (2016). Bioprinting and differentiation of stem cells. Molecules 21:1188. doi: 10.3390/molecules21091188

Isobe, N., Komamiya, T., Kimura, S., Kim, U. J., and Wada, M. (2018). Cellulose hydrogel with tunable shape and mechanical properties: from rigid cylinder to soft scaffold. Int. J. Biol. Macromol. 117, 625-631. doi: 10.1016/j.ijbiomac.2018. 05.071

Isobe, N., Sekine, M., Kimura, S., Wada, M., and Kuga, S. (2011). Anomalous reinforcing effects in cellulose gel-based polymeric nanocomposites. Cellulose 18, 327-333. doi: 10.1007/s10570-010-9487-9486

Jahn, S., Seror, J., and Klein, J. (2016). Lubrication of articular cartilage. Annu. Rev. Biomed. Eng. 18, 235-258. doi: 10.1146/annurev-bioeng-081514-123305

Jain, E., Hill, L., Canning, E., Sell, S. A., and Zustiak, S. P. (2017). Control of gelation, degradation and physical properties of polyethylene glycol hydrogels through the chemical and physical identity of the crosslinker. J. Mater. Chem B 5, 2679-2691. doi: 10.1039/c6tb03050e

Janda, K. D., and Han, H. (1996). Combinatorial chemistry: a liquid-phase approach. Methods Enzymol. 267, 234-247. doi: 10.1016/s0076-6879(96)6701667015 
Ji, D., Jiang, L., and Li, Y. (2018). MiR-192-5p suppresses the growth of bladder cancer cells via targeting Yin Yang 1. Hum. Cell 31, 210-219. doi: 10.1007/ s13577-018-0201-206

Ji, X. F., Zhu, H., Zhao, L. M., and Xiao, J. (2018). Recent advances in 3D bioprinting for the regeneration of functional cartilage. Regenerat. Med. 13, 73-87. doi: 10.2217/rme-2017-2106

Jung, I. Y., Kim, J. S., Choi, B. R., Lee, K., and Lee, H. (2017). Hydrogel based biosensors for in vitro diagnostics of biochemicals, proteins, and genes. $A d v$. Healthc. Mater. 6:1601475. doi: 10.1002/adhm.201601475

Kang, H. J., Peng, J., Lu, S. B., Liu, S. Y., Zhang, L., Huang, J. X., et al. (2014). In vivo cartilage repair using adipose-derived stem cell-loaded decellularized cartilage ECM scaffolds. J. Tissue Eng. Regenerat. Med. 8, 442-453. doi: 10.1002/term. 1538

Karim, A. A., Dou, Q., Li, Z., and Loh, X. J. (2016). Emerging supramolecular therapeutic carriers based on host-guest interactions. Chem. Asian J. 11, 13001321. doi: 10.1002/asia.201501434

Kazemi, D., Shams Asenjan, K., Dehdilani, N., and Parsa, H. (2017). Canine articular cartilage regeneration using mesenchymal stem cells seeded on platelet rich fibrin: macroscopic and histological assessments. Bone Joint Res. 6, 98-107. doi: 10.1302/2046-3758.62.BJR-2016-0188.R1

Keller, L., Regiel-Futyra, A., Gimeno, M., Eap, S., Mendoza, G., Andreu, V., et al. (2017). Chitosan-based nanocomposites for the repair of bone defects. Nanomedicine 13, 2231-2240. doi: 10.1016/j.nano.2017.06.007

Kerschenmeyer, A., Arlov, O., Malheiro, V., Steinwachs, M., Rottmar, M., ManiuraWeber, K., et al. (2017). Anti-oxidant and immune-modulatory properties of sulfated alginate derivatives on human chondrocytes and macrophages. Biomater. Sci. 5, 1756-1765. doi: 10.1039/c7bm00341b

Kesti, M., Muller, M., Becher, J., Schnabelrauch, M., D’Este, M., Eglin, D., et al. (2015). A versatile bioink for three-dimensional printing of cellular scaffolds based on thermally and photo-triggered tandem gelation. Acta Biomater. 11, 162-172. doi: 10.1016/j.actbio.2014.09.033

Kim, U. J., Park, J., Kim, H. J., Wada, M., and Kaplan, D. L. (2005). Three-dimensional aqueous-derived biomaterial scaffolds from silk fibroin. Biomaterials 26, 2775-2785. doi: 10.1016/j.biomaterials.2004.07.044

Kim, W. K., Choi, J. H., Shin, M. E., Kim, J. W., Kim, P. Y., Kim, N., et al. (2019). Evaluation of cartilage regeneration of chondrocyte encapsulated gellan gumbased hyaluronic acid blended hydrogel. Int. J. Biol. Macromol. 141, 51-59. doi: 10.1016/j.ijbiomac.2019.08.176

Kim, Y. S., Majid, M., Melchiorri, A. J., and Mikos, A. G. (2019). Applications of decellularized extracellular matrix in bone and cartilage tissue engineering. Bioeng. Transl. Med. 4, 83-95. doi: 10.1002/btm2.10110

Kim, Y. B., Lee, H., and Kim, G. H. (2016). Strategy to achieve highly porous/biocompatible macroscale cell blocks, using a collagen/genipin-bioink and an optimal 3D printing process. ACS Appl. Mater. Interfaces 8, 3223032240. doi: 10.1021/acsami.6b11669

Klein, A. M., Graham, V. L., Gulleth, Y., and Lafreniere, D. (2005). Polyglycolic acid/poly-L-lactic acid copolymer use in laryngotracheal reconstruction: a rabbit model. Laryngoscope 115, 583-587. doi: 10.1097/01.mlg.0000161342. $77386.8 \mathrm{~b}$

Klemm, D., Kramer, F., Moritz, S., Lindstrom, T., Ankerfors, M., Gray, D., et al. (2011). Nanocelluloses: a new family of nature-based materials. Angew Chem. Int. Ed Engl. 50, 5438-5466. doi: 10.1002/anie.201001273

Ko, H. F., Sfeir, C., and Kumta, P. N. (2010). Novel synthesis strategies for natural polymer and composite biomaterials as potential scaffolds for tissue engineering. Philos. Trans. R. Soc. Mathemat. Phys. Eng. Sci. 368, 1981-1997. doi: 10.1098/rsta.2010.0009

Kobayashi, E., Fluckiger, L., Fujioka-Kobayashi, M., Sawada, K., Sculean, A., Schaller, B., et al. (2016). Comparative release of growth factors from PRP, PRF, and advanced-PRF. Clin. Oral. Investig. 20, 2353-2360. doi: 10.1007/s00784016-1719-1711

Kobayashi, Y., Saito, T., and Isogai, A. (2014). Aerogels with 3D ordered nanofiber skeletons of liquid-crystalline nanocellulose derivatives as tough and transparent insulators. Angewandte Chemie-Int. Ed. 53, 10394-10397. doi: 10. 1002/anie.201405123

Kontturi, L. S., Jarvinen, E., Muhonen, V., Collin, E. C., Pandit, A. S., Kiviranta, I., et al. (2014). An injectable, in situ forming type II collagen/hyaluronic acid hydrogel vehicle for chondrocyte delivery in cartilage tissue engineering. Drug Deliv. Transl. Res. 4, 149-158. doi: 10.1007/s13346-013-0188-181
Koshy, S. T., Desai, R. M., Joly, P., Li, J., Bagrodia, R. K., Lewin, S. A., et al. (2016). Click-Crosslinked injectable gelatin hydrogels. Adv. Healthc. Mater. 5, 541-547. doi: 10.1002/adhm.201500757

Kresse, H., and Schonherr, E. (2001). Proteoglycans of the extracellular matrix and growth control. J. Cell Physiol. 189, 266-274. doi: 10.1002/jcp.10030

Krill, M., Early, N., Everhart, J. S., and Flanigan, D. C. (2018). Autologous Chondrocyte Implantation (ACI) for knee cartilage defects: a review of indications. technique, and outcomes. JBJS Rev. 6:e5. doi: 10.2106/JBJS.RVW. 17.00078

Kundu, B., Rajkhowa, R., Kundu, S. C., and Wang, X. (2013). Silk fibroin biomaterials for tissue regenerations. Adv. Drug Deliv. Rev. 65, 457-470. doi: 10.1016/j.addr.2012.09.043

Kundu, J., Shim, J. H., Jang, J., Kim, S. W., and Cho, D. W. (2015). An additive manufacturing-based PCL-alginate-chondrocyte bioprinted scaffold for cartilage tissue engineering. J. Tissue Eng. Regen. Med. 9, 1286-1297. doi: $10.1002 /$ term. 1682

Kundu, S. C., Kundu, B., Talukdar, S., Bano, S., Nayak, S., Kundu, J., et al. (2012). Invited review nonmulberry silk biopolymers. Biopolymers 97, 455-467. doi: 10.1002/bip.22024

Kuroda, R., Ishida, K., Matsumoto, T., Akisue, T., Fujioka, H., Mizuno, K., et al. (2007). Treatment of a full-thickness articular cartilage defect in the femoral condyle of an athlete with autologous bone-marrow stromal cells. Osteoarthritis Cartilage 15, 226-231. doi: 10.1016/j.joca.2006.08.008

Kutikov, A. B., Skelly, J. D., Ayers, D. C., and Song, J. (2015). Templated repair of long bone defects in rats with bioactive spiral-wrapped electrospun amphiphilic polymer/hydroxyapatite scaffolds. ACS Appl. Mater. Interfaces 7, 4890-4901. doi: $10.1021 / \mathrm{am} 508984 \mathrm{y}$

Lam, A. T. L., Reuveny, S., and Oh, S. K. (2020). Human mesenchymal stem cell therapy for cartilage repair: review on isolation, expansion, and constructs. Stem Cell Res. 44:101738. doi: 10.1016/j.scr.2020.101738

Larsen, M., Artym, V. V., Green, J. A., and Yamada, K. M. (2006). The matrix reorganized: extracellular matrix remodeling and integrin signaling. Curr. Opin. Cell Biol. 18, 463-471. doi: 10.1016/j.ceb.2006.08.009

Lavoine, N., Desloges, I., Dufresne, A., and Bras, J. (2012). Microfibrillated cellulose - its barrier properties and applications in cellulosic materials: a review. Carbohydr. Polym. 90, 735-764. doi: 10.1016/j.carbpol.2012.05.026

Lee, C. H., Singla, A., and Lee, Y. (2001). Biomedical applications of collagen. Int. J. Pharm. 221, 1-22. doi: 10.1016/s0378-5173(01)00691-693

Lee, H. J., Lee, J. S., Chansakul, T., Yu, C., Elisseeff, J. H., and Yu, S. M. (2006). Collagen mimetic peptide-conjugated photopolymerizable PEG hydrogel. Biomaterials 27, 5268-5276. doi: 10.1016/j.biomaterials.2006.06.001

Lee, J., Yeo, M., Kim, W., Koo, Y., and Kim, G. H. (2018). Development of a tannic acid cross-linking process for obtaining $3 \mathrm{D}$ porous cell-laden collagen structure. Int. J. Biol. Macromol. 110, 497-503. doi: 10.1016/j.ijbiomac.2017.10.105

Lee, K. Y., and Mooney, D. J. (2012). Alginate: properties and biomedical applications. Prog. Polym. Sci. 37, 106-126. doi: 10.1016/j.progpolymsci.2011. 06.003

Lee, S. H., and Shin, H. (2007). Matrices and scaffolds for delivery of bioactive molecules in bone and cartilage tissue engineering. Adv. Drug Deliv. Rev. 59, 339-359. doi: 10.1016/j.addr.2007.03.016

Levingstone, T. J., Thompson, E., Matsiko, A., Schepens, A., Gleeson, J. P., and O’Brien, F. J. (2016). Multi-layered collagen-based scaffolds for osteochondral defect repair in rabbits. Acta Biomater. 32, 149-160. doi: 10.1016/j.actbio.2015. 12.034

Levy, Y. D., Gortz, S., Pulido, P. A., McCauley, J. C., and Bugbee, W. D. (2013). Do fresh osteochondral allografts successfully treat femoral condyle lesions? Clin. Orthop Relat. Res. 471, 231-237. doi: 10.1007/s11999-012-2556-2554

Li, F., Truong, V. X., Thissen, H., Frith, J. E., and Forsythe, J. S. (2017). Microfluidic encapsulation of human mesenchymal stem cells for articular cartilage tissue regeneration. ACS Appl. Mater. Interfaces 9, 8589-8601. doi: 10.1021/acsami. $7 \mathrm{~b} 00728$

Li, X., Chen, Y., Kawazoe, N., and Chen, G. (2017). Influence of microporous gelatin hydrogels on chondrocyte functions. J. Mater. Chem. B 5, 5753-5762. doi: $10.1039 / \mathrm{c} 7 \mathrm{tb} 01350 \mathrm{~g}$

Li, J., Hansen, K. C., Zhang, Y., Dong, C., Dinu, C. Z., Dzieciatkowska, M., et al. (2014). Rejuvenation of chondrogenic potential in a young stem cell microenvironment. Biomaterials 35, 642-653. doi: 10.1016/j.biomaterials.2013. 09.099 
Li, Y. Y., Cheng, H. W., Cheung, K. M., Chan, D., and Chan, B. P. (2014). Mesenchymal stem cell-collagen microspheres for articular cartilage repair: cell density and differentiation status. Acta Biomater 10, 1919-1929. doi: 10.1016/j. actbio.2014.01.002

Li, J., Narayanan, K., Zhang, Y., Hill, R. C., He, F., Hansen, K. C., et al. (2020). Role of lineage-specific matrix in stem cell chondrogenesis. Biomaterials 231:119681. doi: 10.1016/j.biomaterials.2019.119681

Li, L., Yu, F., Zheng, L., Wang, R., Yan, W., Wang, Z., et al. (2019). Natural hydrogels for cartilage regeneration: modification, preparation and application. J. Orthop Trans. 17, 26-41. doi: 10.1016/j.jot.2018.09.003

Li, S., Tian, X., Fan, J., Tong, H., Ao, Q., and Wang, X. (2019). Chitosans for tissue repair and organ three-dimensional (3D) bioprinting. Micromachines (Basel) 10:765. doi: 10.3390/mi10110765

Li, R. Y., Liu, Z. G., Liu, H. Q., Chen, L., Liu, J. F., and Pan, Y. H. (2015). Evaluation of biocompatibility and toxicity of biodegradable poly (DL-lactic acid) films. Am. J. Transl. Res. 7, 1357-1370.

Li, W. J., Chiang, H., Kuo, T. F., Lee, H. S., Jiang, C. C., and Tuan, R. S. (2009). Evaluation of articular cartilage repair using biodegradable nanofibrous scaffolds in a swine model: a pilot study. J. Tissue Eng. Regen. Med. 3, 1-10. doi: 10.1002/term.127

Li, W. J., Cooper, J. A. Jr., Mauck, R. L., and Tuan, R. S. (2006). Fabrication and characterization of six electrospun poly(alpha-hydroxy ester)-based fibrous scaffolds for tissue engineering applications. Acta Biomater. 2, 377-385. doi: 10.1016/j.actbio.2006.02.005

Li, Z. B., Muiruri, J. K., Thitsartarn, W., Zhang, X., Tan, B. H., and He, C. B. (2018). Biodegradable silica rubber core-shell nanoparticles and their stereocomplex for efficient PLA toughening. Composites Sci. Technol. 159, 11-17. doi: 10.1016/ j.compscitech.2018.02.026

Liang, J., Li, X., Zhang, H., Wang, D., Feng, X., Wang, H., et al. (2012). Allogeneic mesenchymal stem cells transplantation in patients with refractory RA. Clin. Rheumatol. 31, 157-161. doi: 10.1007/s10067-011-18161810

Lin, H., Beck, A. M., Shimomura, K., Sohn, J., Fritch, M. R., Deng, Y., et al. (2019). Optimization of photocrosslinked gelatin/hyaluronic acid hybrid scaffold for the repair of cartilage defect. J. Tissue Eng. Regen. Med. 13, 1418-1429. doi: $10.1002 /$ term. 2883

Lin, X., Wang, W., Zhang, W., Zhang, Z., Zhou, G., Cao, Y., et al. (2017). Hyaluronic Acid Coating Enhances Biocompatibility of Nonwoven PGA Scaffold and Cartilage Formation. Tissue Eng. Part C Methods 23, 86-97. doi: 10.1089/ten.TEC.2016.0373

Liu, L., Gao, Y., Zhao, J., Yuan, L., Li, C., Liu, Z., et al. (2018). A mild method for surface-grafting PEG Onto Segmented Poly(Ester-Urethane) film with high grafting density for biomedical purpose. Polymers (Basel) 10:1125. doi: 10.3390/ polym 10101125

Liu, M., Zeng, X., Ma, C., Yi, H., Ali, Z., Mou, X., et al. (2017). Injectable hydrogels for cartilage and bone tissue engineering. Bone Res. 5:17014. doi: 10.1038/ boneres.2017.14

Liu, Y., Luo, D., and Wang, T. (2016). Hierarchical structures of bone and bioinspired bone tissue Engineering. Small 12, 4611-4632. doi: 10.1002/smll. 201600626

Liu, Y., Shu, X. Z., and Prestwich, G. D. (2006). Osteochondral defect repair with autologous bone marrow-derived mesenchymal stem cells in an injectable, in situ, cross-linked synthetic extracellular matrix. Tissue Eng. 12, 3405-3416. doi: 10.1089/ten.2006.12.3405

Lopes, M. S., Jardini, A. L., and Filho, R. M. (2012). Poly (Lactic Acid) production for tissue engineering applications. Procedia Eng. 42, 1402-1413. doi: 10.1016/j. proeng.2012.07.534

Luo, L., Eswaramoorthy, R., Mulhall, K. J., and Kelly, D. J. (2015). Decellularization of porcine articular cartilage explants and their subsequent repopulation with human chondroprogenitor cells. J. Mech. Behav. Biomed. Mater. 55, 21-31. doi: 10.1016/j.jmbbm.2015.10.002

Ma, D., Wang, Y., and Dai, W. (2018). Silk fibroin-based biomaterials for musculoskeletal tissue engineering. Mater. Sci. Eng. C Mater. Biol. Appl. 89, 456-469. doi: 10.1016/j.msec.2018.04.062

Ma, K., Titan, A. L., Stafford, M., Zheng, C., and Levenston, M. E. (2012). Variations in chondrogenesis of human bone marrow-derived mesenchymal stem cells in fibrin/alginate blended hydrogels. Acta Biomater. 8, 3754-3764. doi: 10.1016/j. actbio.2012.06.028
Mahboob, S. (2015). Isolation and characterization of collagen from fish waste material- skin, scales and fins of Catla catla and Cirrhinus mrigala. J. Food Sci. Technol. 52, 4296-4305. doi: 10.1007/s13197-014-1520-1526

Maia, F. R., Carvalho, M. R., Oliveira, J. M., and Reis, R. L. (2018). Tissue engineering strategies for osteochondral repair. Adv. Exp. Med. Biol. 1059, 353-371. doi: 10.1007/978-3-319-76735-2_16

Makris, E. A., Gomoll, A. H., Malizos, K. N., Hu, J. C., and Athanasiou, K. A. (2015). Repair and tissue engineering techniques for articular cartilage. Nat. Rev. Rheumatol. 11, 21-34. doi: 10.1038/nrrheum.2014.157

Maldonado, M., and Nam, J. (2013). The role of changes in extracellular matrix of cartilage in the presence of inflammation on the pathology of osteoarthritis. Biomed. Res. Int. 2013:284873. doi: 10.1155/2013/284873

Mallick, S. P., Singh, B. N., Rastogi, A., and Srivastava, P. (2018). Design and evaluation of chitosan/poly(l-lactide)/pectin based composite scaffolds for cartilage tissue regeneration. Int. J. Biol. Macromol. 112, 909-920. doi: 10.1016/ j.ijbiomac.2018.02.049

Mandelbaum, B., Browne, J. E., Fu, F., Micheli, L. J., Moseley, J. B. Jr., et al. (2007). Treatment outcomes of autologous chondrocyte implantation for full-thickness articular cartilage defects of the trochlea. Am. J. Sports Med. 35, 915-921. doi: 10.1177/0363546507299528

Marques, C. F., Diogo, G. S., Pina, S., Oliveira, J. M., Silva, T. H., and Reis, R. L. (2019). Collagen-based bioinks for hard tissue engineering applications: a comprehensive review. J. Mater. Sci. Mater. Med. 30:32. doi: 10.1007/s10856019-6234-x

Marycz, K., Maredziak, M., Grzesiak, J., Lis, A., and Smieszek, A. (2016). Biphasic polyurethane/polylactide sponges doped with nano-Hydroxyapatite (nHAp) combined with human adipose-derived mesenchymal stromal stem cells for regenerative medicine applications. Polymers (Basel) 8:339. doi: 10. 3390/polym8100339

Marycz, K., Smieszek, A., Targonska, S., Walsh, S. A., Szustakiewicz, K., and Wiglusz, R. J. (2020). Three dimensional (3D) printed polylactic acid with nano-hydroxyapatite doped with europium(III) ions (nHAp/PLLA@Eu(3+)) composite for osteochondral defect regeneration and theranostics. Mater. Sci. Eng. C Mater. Biol. Appl. 110:110634. doi: 10.1016/j.msec.2020.110634

McDermott, I. D. (2019). Patellar chondral defect treatment with a cellfree polyglycolic acid-hyaluronan-based implant and platelet-rich fibrin glue after previously failed microfracture. SAGE Open Med. Case Rep. 7:2050313X18823470. doi: 10.1177/2050313X18823470

McNamara, J. T., Morgan, J. L., and Zimmer, J. (2015). A molecular description of cellulose biosynthesis. Annu. Rev. Biochem. 84, 895-921. doi: 10.1146/annurevbiochem-060614-33930

Meinel, L., and Kaplan, D. L. (2012). Silk constructs for delivery of musculoskeletal therapeutics. Adv. Drug Deliv. Rev. 64, 1111-1122. doi: 10.1016/j.addr.2012. 03.016

Meng, W., Gao, L., Venkatesan, J. K., Wang, G., Madry, H., and Cucchiarini, M. (2019). Translational applications of photopolymerizable hydrogels for cartilage repair. J. Exp. Orthop 6:47. doi: 10.1186/s40634-019-0215-213

Minas, T., Ogura, T., and Bryant, T. (2016). Autologous chondrocyte implantation. JBJS Essent Surg. Tech. 6:e24. doi: 10.2106/JBJS.ST.16.00018

Miron, R. J., Fujioka-Kobayashi, M., Hernandez, M., Kandalam, U., Zhang, Y., Ghanaati, S., et al. (2017). Injectable platelet rich fibrin (i-PRF): opportunities in regenerative dentistry? Clin. Oral Invest. 21, 2619-2627. doi: 10.1007/s00784017-2063-2069

Miron, R. J., and Zhang, Y. (2018). Autologous liquid platelet rich fibrin: a novel drug delivery system. Acta Biomater. 75, 35-51. doi: 10.1016/j.actbio.2018. 05.021

Mohammadinejad, R., Kumar, A., Ranjbar-Mohammadi, M., Ashrafizadeh, M., Han, S. S., Khang, G., et al. (2020). Recent advances in natural gum-based biomaterials for tissue engineering and regenerative medicine: a review. Polymers (Basel) 12:176. doi: 10.3390/polym12010176

Moon, R. J., Martini, A., Nairn, J., Simonsen, J., and Youngblood, J. (2011). Cellulose nanomaterials review: structure, properties and nanocomposites. Chem. Soc. Rev. 40, 3941-3994. doi: 10.1039/c0cs00108b

Morseburg, K., and Chinga-Carrasco, G. (2009). Assessing the combined benefits of clay and nanofibrillated cellulose in layered TMP-based sheets. Cellulose 16, 795-806. doi: 10.1007/s10570-009-9290-9294

Mostafa, S., Pakvasa, M., Coalson, E., Zhu, A., Alverdy, A., Castillo, H., et al. (2019). The wonders of BMP9: from mesenchymal stem cell differentiation, 
angiogenesis, neurogenesis, tumorigenesis, and metabolism to regenerative medicine. Genes Dis. 6, 201-223. doi: 10.1016/j.gendis.2019.07.003

Moura, C. S., Silva, J. C., Faria, S., Fernandes, P. R., da Silva, C. L., Cabral, J. M. S., et al. (2020). Chondrogenic differentiation of mesenchymal stem/stromal cells on $3 \mathrm{D}$ porous poly (epsilon-caprolactone) scaffolds: effects of material alkaline treatment and chondroitin sulfate supplementation. J. Biosci. Bioeng. 129, 756-764. doi: 10.1016/j.jbiosc.2020.01.004

Mouser, V. H. M., Dautzenberg, N. M. M., Levato, R., van Rijen, M. H. P., Dhert, W. J. A., Malda, J., et al. (2018). Ex vivo model unravelling cell distribution effect in hydrogels for cartilage repair. ALTEX 35, 65-76. doi: 10.14573/altex.1704171

Murphy, S. V., and Atala, A. (2014). 3D bioprinting of tissues and organs. Nat. Biotechnol. 32, 773-785. doi: 10.1038/nbt.2958

Muzzarelli, R. A., Greco, F., Busilacchi, A., Sollazzo, V., and Gigante, A. (2012). Chitosan, hyaluronan and chondroitin sulfate in tissue engineering for cartilage regeneration: a review. Carbohydr. Polym. 89, 723-739. doi: 10.1016/j.carbpol. 2012.04.057

Nagai, T., Yamashita, E., Taniguchi, K., Kanamori, N., and Suzuki, N. (2001). Isolation and characterisation of collagen from the outer skin waste material of cuttlefish (Sepia lycidas). Food Chem. 72, 425-429. doi: 10.1016/S0308-8146(00) 00249-241

Nakao, H., Jacquet, R. D., Shasti, M., Isogai, N., Murthy, A. S., and Landis, W. J. (2017). Long-Term comparison between human normal conchal and microtia chondrocytes regenerated by tissue engineering on nanofiber polyglycolic acid scaffolds. Plastic Reconstruct. Surg. 139:911e-921e.

Nakayama, A., Kakugo, A., Gong, J. P., Osada, Y., Takai, M., Erata, T., et al. (2004). High mechanical strength double-network hydrogel with bacterial cellulose. Adv. Funct. Mater. 14, 1124-1128. doi: 10.1002/adfm.200305197

Nazarov, R., Jin, H. J., and Kaplan, D. L. (2004). Porous 3-D scaffolds from regenerated silk fibroin. Biomacromolecules 5, 718-726. doi: 10.1021/ bm034327e

Ngo, T. D., Kashani, A., Imbalzano, G., Nguyen, K. T. Q., and Hui, D. (2018). Additive manufacturing (3D printing): a review of materials, methods, applications and challenges. Composites Part B-Eng. 143, 172-196. doi: 10.1016/ j.compositesb.2018.02.012

Nichol, J. W., Koshy, S. T., Bae, H., Hwang, C. M., Yamanlar, S., and Khademhosseini, A. (2010). Cell-laden microengineered gelatin methacrylate hydrogels. Biomaterials 31, 5536-5544. doi: 10.1016/j.biomaterials.2010.03.064

Novak, T., Fites Gilliland, K., Xu, X., Worke, L., Ciesielski, A., Breur, G., et al. (2016). In vivo cellular infiltration and remodeling in a decellularized ovine osteochondral allograft. Tissue Eng. Part A 22, 1274-1285. doi: 10.1089/ten. TEA.2016.0149

Oh, S. H., Kim, T. H., Im, G. I., and Lee, J. H. (2010). Investigation of pore size effect on chondrogenic differentiation of adipose stem cells using a pore size gradient scaffold. Biomacromolecules 11, 1948-1955. doi: 10.1021/bm100199m

Ostadal, B., Kolar, F., Pelouch, V., and Widimsky, J. (1995). Ontogenetic differences in cardiopulmonary adaptation to chronic hypoxia. Physiol. Res. 44, 45-51.

O'Sullivan, A. C. (1997). Cellulose: the structure slowly unravels. Cellulose 4, 173-207. doi: 10.1023/a:1018431705579

Ousema, P. H., Moutos, F. T., Estes, B. T., Caplan, A. I., Lennon, D. P., Guilak, F., et al. (2012). The inhibition by interleukin 1 of MSC chondrogenesis and the development of biomechanical properties in biomimetic 3D woven PCL scaffolds. Biomaterials 33, 8967-8974. doi: 10.1016/j.biomaterials.2012.08.045

Ozbolat, I. T. (2015). Scaffold-Based or scaffold-free bioprinting: competing or complementing approaches? J. Nanotechnol. Eng. Med. 6:024701. doi: 10.1115/ 1.4030414

Pahlevanzadeh, F., Bakhsheshi-Rad, H. R., and Hamzah, E. (2018). In-vitro biocompatibility, bioactivity, and mechanical strength of PMMA-PCL polymer containing fluorapatite and graphene oxide bone cements. J. Mech. Behav. Biomed. Mater. 82, 257-267. doi: 10.1016/j.jmbbm.2018.03.016

Pakvasa, M., Haravu, P., Boachie-Mensah, M., Jones, A., Coalson, E., Liao, J., et al. (2021). Notch signaling: its essential roles in bone and craniofacial development. Genes Dis. 8, 8-24. doi: 10.1016/j.gendis.2020.04.006

Park, H., and Lee, K. Y. (2014). Cartilage regeneration using biodegradable oxidized alginate/hyaluronate hydrogels. J. Biomed. Mater. Res. A 102, 4519-4525. doi: 10.1002/jbm.a.35126

Patra, C., Talukdar, S., Novoyatleva, T., Velagala, S. R., Muhlfeld, C., Kundu, B., et al. (2012). Silk protein fibroin from Antheraea mylitta for cardiac tissue engineering. Biomaterials 33, 2673-2680. doi: 10.1016/j.biomaterials.2011. 12.036

Pei, M., and He, F. (2012). Extracellular matrix deposited by synovium-derived stem cells delays replicative senescent chondrocyte dedifferentiation and enhances redifferentiation. J. Cell Physiol. 227, 2163-2174. doi: 10.1002/jcp. 22950

Peterson, L., Minas, T., Brittberg, M., Nilsson, A., Sjogren-Jansson, E., and Lindahl, A. (2000). Two- to 9-year outcome after autologous chondrocyte transplantation of the knee. Clin. Orthop Relat. Res. 374, 212-234. doi: 10.1097/ 00003086-200005000-200005020

Pillai, M. M., Gopinathan, J., Selvakumar, R., and Bhattacharyya, A. (2018). Human knee meniscus regeneration strategies: a review on recent advances. Curr. Osteoporos Rep. 16, 224-235. doi: 10.1007/s11914-018-0436-x

Pittenger, M. F., Discher, D. E., Peault, B. M., Phinney, D. G., Hare, J. M., and Caplan, A. I. (2019). Mesenchymal stem cell perspective: cell biology to clinical progress. NPJ Regen. Med. 4:22. doi: 10.1038/s41536-019-0083-86

Ra, J. C., Kang, S. K., Shin, I. S., Park, H. G., Joo, S. A., Kim, J. G., et al. (2011). Stem cell treatment for patients with autoimmune disease by systemic infusion of culture-expanded autologous adipose tissue derived mesenchymal stem cells. J. Transl. Med. 9:181. doi: 10.1186/1479-5876-9-181

Rastegar, F., Shenaq, D., Huang, J., Zhang, W., Zhang, B. Q., He, B. C., et al. (2010). Mesenchymal stem cells: molecular characteristics and clinical applications. World J. Stem. Cells 2, 67-80. doi: 10.4252/wjsc.v2.i4.67

Rehm, B. H., and Valla, S. (1997). Bacterial alginates: biosynthesis and applications. Appl. Microbiol. Biotechnol. 48, 281-288. doi: 10.1007/s002530051051

Revati, R., Abdul Majid, M. S., Ridzuan, M. J. M., Normahira, M., Mohd Nasir, N. F., Rahman, Y. M., et al. (2017). Mechanical, thermal and morphological characterisation of 3D porous Pennisetum purpureum/PLA biocomposites scaffold. Mater. Sci. Eng. C Mater. Biol. Appl. 75, 752-759. doi: 10.1016/j.msec. 2017.02.127

Rich, A. M., Pearlstein, E., Weissmann, G., and Hoffstein, S. T. (1981). Cartilage proteoglycans inhibit fibronectin-mediated adhesion. Nature 293, 224-226. doi: $10.1038 / 293224 \mathrm{a} 0$

Rim, Y. A., Nam, Y., Park, N., Lee, J., Park, S. H., and Ju, J. H. (2018). Repair potential of nonsurgically delivered induced pluripotent stem cell-derived chondrocytes in a rat osteochondral defect model. J. Tissue Eng. Regen. Med. 12, 1843-1855. doi: 10.1002/term.2705

Roberts, J. J., and Bryant, S. J. (2013). Comparison of photopolymerizable thiol-ene PEG and acrylate-based PEG hydrogels for cartilage development. Biomaterials 34, 9969-9979. doi: 10.1016/j.biomaterials.2013.09.020

Rodriguez-Vazquez, M., Vega-Ruiz, B., Ramos-Zuniga, R., Saldana-Koppel, D. A., and Quinones-Olvera, L. F. (2015). Chitosan and its potential use as a scaffold for tissue engineering in regenerative medicine. Biomed. Res. Int. 2015:821279. doi: $10.1155 / 2015 / 821279$

Roseti, L., Cavallo, C., Desando, G., Parisi, V., Petretta, M., Bartolotti, I., et al. (2018). Three-Dimensional bioprinting of cartilage by the use of stem cells: a strategy to improve regeneration. Materials (Basel) 11:1749. doi: 10.3390/ ma11091749

Roseti, L., Parisi, V., Petretta, M., Cavallo, C., Desando, G., Bartolotti, I., et al. (2017). Scaffolds for bone tissue engineering: state of the art and new perspectives. Mater. Sci. Eng. C Mater. Biol. Appl. 78, 1246-1262. doi: 10.1016/j. msec.2017.05.017

Rothrauff, B. B., Yang, G., and Tuan, R. S. (2017). Tissue-specific bioactivity of soluble tendon-derived and cartilage-derived extracellular matrices on adult mesenchymal stem cells. Stem Cell Res. Ther. 8:133. doi: 10.1186/s13287-0170580-588

Rowland, C. R., Colucci, L. A., and Guilak, F. (2016). Fabrication of anatomicallyshaped cartilage constructs using decellularized cartilage-derived matrix scaffolds. Biomaterials 91, 57-72. doi: 10.1016/j.biomaterials.2016.03.012

Saghebasl, S., Davaran, S., Rahbarghazi, R., Montaseri, A., Salehi, R., and Ramazani, A. (2018). Synthesis and in vitro evaluation of thermosensitive hydrogel scaffolds based on (PNIPAAm-PCL-PEG-PCL-PNIPAAm)/Gelatin and (PCLPEG-PCL)/Gelatin for use in cartilage tissue engineering. J. Biomater. SciencePolymer Ed. 29, 1185-1206. doi: 10.1080/09205063.2018.1447627

Sajkiewicz, P., and Kolbuk, D. (2014). Electrospinning of gelatin for tissue engineering-molecular conformation as one of the overlooked problems. J. Biomater. Sci. Polym. Ed. 25, 2009-2022. doi: 10.1080/09205063.2014.975392 
Saroia, J., Wang, Y. E., Wei, Q. H., Zhang, K., Lu, T. L., and Zhang, B. (2018). A review on biocompatibility nature of hydrogels with $3 \mathrm{D}$ printing techniques, tissue engineering application and its future prospective. Bio-Design Manufact. 1, 265-279. doi: 10.1007/s42242-018-0029-27

Schaefer, D., Martin, I., Shastri, P., Padera, R. F., Langer, R., Freed, L. E., et al. (2000). In vitro generation of osteochondral composites. Biomaterials 21, 25992606. doi: 10.1016/s0142-9612(00)00127-7

Schwarz, S., Koerber, L., Elsaesser, A. F., Goldberg-Bockhorn, E., Seitz, A. M., Durselen, L., et al. (2012). Decellularized cartilage matrix as a novel biomatrix for cartilage tissue-engineering applications. Tissue Eng. Part A 18, 2195-2209. doi: 10.1089/ten.tea.2011.0705

Senaratne, L. S., Park, P. J., and Kim, S. K. (2006). Isolation and characterization of collagen from brown backed toadfish (Lagocephalus gloveri) skin. Bioresour. Technol. 97, 191-197. doi: 10.1016/j.biortech.2005.02.024

Sengupta, S., Park, S. H., Seok, G. E., Patel, A., Numata, K., Lu, C. L., et al. (2010). Quantifying osteogenic cell degradation of silk biomaterials. Biomacromolecules 11, 3592-3599. doi: 10.1021/bm101054q

Shafiee, A., Soleimani, M., Chamheidari, G. A., Seyedjafari, E., Dodel, M., Atashi, A., et al. (2011). Electrospun nanofiber-based regeneration of cartilage enhanced by mesenchymal stem cells. J. Biomed. Mater. Res. A 99, 467-478. doi: $10.1002 / j b m . a .33206$

Sheu, S. Y., Wang, C. H., Pao, Y. H., Fu, Y. T., Liu, C. H., Yao, C. H., et al. (2017). The effect of platelet-rich fibrin on autologous osteochondral transplantation: an in vivo porcine model. Knee 24, 1392-1401. doi: 10.1016/j.knee.2017.08.049

Silva, L. H. D., Lima, E., Miranda, R. B. P., Favero, S. S., Lohbauer, U., and Cesar, P. F. (2017). Dental ceramics: a review of new materials and processing methods. Braz. Oral. Res. 31(Suppl. 1):e58. doi: 10.1590/1807-3107BOR-2017. vol31.0058

Silva, T. H., Moreira-Silva, J., Marques, A. L., Domingues, A., Bayon, Y., and Reis, R. L. (2014). Marine origin collagens and its potential applications. Mar. Drugs 12, 5881-5901. doi: 10.3390/md12125881

Smieszek, A., Marycz, K., Szustakiewicz, K., Kryszak, B., Targonska, S., Zawisza, K., et al. (2019). New approach to modification of poly (l-lactic acid) with nanohydroxyapatite improving functionality of human adipose-derived stromal cells (hASCs) through increased viability and enhanced mitochondrial activity. Mater. Sci. Eng. C Mater. Biol. Appl. 98, 213-226. doi: 10.1016/j.msec.2018. 12.099

Solheim, E., Hegna, J., Oyen, J., Harlem, T., and Strand, T. (2013). Results at 10 to 14 years after osteochondral autografting (mosaicplasty) in articular cartilage defects in the knee. Knee 20, 287-290. doi: 10.1016/j.knee.2013.01.001

Song, E., Yeon Kim, S., Chun, T., Byun, H. J., and Lee, Y. M. (2006). Collagen scaffolds derived from a marine source and their biocompatibility. Biomaterials 27, 2951-2961. doi: 10.1016/j.biomaterials.2006.01.015

Sousa, I., Mendes, A., Pereira, R. F., and Bártolo, P. J. (2014). Collagen surface modified poly( $\varepsilon$-caprolactone) scaffolds with improved hydrophilicity and cell adhesion properties. Mater. Lett. 134, 263-267. doi: 10.1016/j.matlet.2014. 06.132

Spiller, K. L., Maher, S. A., and Lowman, A. M. (2011). Hydrogels for the repair of articular cartilage defects. Tissue Eng. Part B Rev. 17, 281-299. doi: 10.1089/ten. TEB.2011.0077

Spratt, D. M., and Haycock, P. (1988). Aspects of the life history of Cercopithifilaria johnstoni (Nematoda:Filarioidea). Int. J. Parasitol. 18, 1087-1092. doi: 10.1016/ 0020-7519(88)90079-90073

Spreafico, A., Chellini, F., Frediani, B., Bernardini, G., Niccolini, S., Serchi, T., et al. (2009). Biochemical investigation of the effects of human platelet releasates on human articular chondrocytes. J. Cell Biochem. 108, 1153-1165. doi: 10.1002/ jcb. 22344

Srinivasan, P. P., McCoy, S. Y., Jha, A. K., Yang, W., Jia, X., Farach-Carson, M. C., et al. (2012). Injectable perlecan domain 1-hyaluronan microgels potentiate the cartilage repair effect of BMP2 in a murine model of early osteoarthritis. Biomed. Mater. 7:024109. doi: 10.1088/1748-6041/7/2/024109

Sriplai, N., Mongkolthanaruk, W., Eichhorn, S. J., and Pinitsoontorn, S. (2018). Magnetically responsive and flexible bacterial cellulose membranes. Carbohydr. Polym. 192, 251-262. doi: 10.1016/j.carbpol.2018.03.072

Steinwachs, M., and Kreuz, P. C. (2007). Autologous chondrocyte implantation in chondral defects of the knee with a type I/III collagen membrane: a prospective study with a 3-year follow-up. Arthroscopy 23, 381-387. doi: 10.1016/j.arthro. 2006.12.003
Stoop, R. (2008). Smart biomaterials for tissue engineering of cartilage. Injury 39(Suppl. 1), S77-S87. doi: 10.1016/j.injury.2008.01.036

$\mathrm{Su}$, C. Y., Kuo, Y. P., Tseng, Y. H., Su, C. H., and Burnouf, T. (2009). In vitro release of growth factors from platelet-rich fibrin (PRF): a proposal to optimize the clinical applications of PRF. Oral. Surg. Oral. Med. Oral. Pathol. Oral. Radiol. Endod. 108, 56-61. doi: 10.1016/j.tripleo.2009.02.004

Sultankulov, B., Berillo, D., Sultankulova, K., Tokay, T., and Saparov, A. (2019). Progress in the development of chitosan-based biomaterials for tissue engineering and regenerative medicine. Biomolecules 9:470. doi: 10.3390/ biom 9090470

Sun, Y., Yan, L., Chen, S., and Pei, M. (2018). Functionality of decellularized matrix in cartilage regeneration: a comparison of tissue versus cell sources. Acta Biomater. 74, 56-73. doi: 10.1016/j.actbio.2018.04.048

Suzuki, H., Araki, K., Matsui, T., Tomifuji, M., Yamashita, T., Kobayashi, Y., et al. (2016). Value of a novel PGA-collagen tube on recurrent laryngeal nerve regeneration in a rat model. Laryngoscope 126, E233-E239. doi: 10.1002/lary. 25750

Svensson, A., Nicklasson, E., Harrah, T., Panilaitis, B., Kaplan, D. L., Brittberg, M., et al. (2005). Bacterial cellulose as a potential scaffold for tissue engineering of cartilage. Biomaterials 26, 419-431. doi: 10.1016/j.biomaterials.2004.02.049

Szyszka, K., Targonska, S., Gazinska, M., Szustakiewicz, K., and Wiglusz, R. J. (2019). The comprehensive approach to preparation and investigation of the $\mathrm{Eu}(3+)$ Doped Hydroxyapatite/poly(L-lactide) nanocomposites: promising materials for theranostics application. Nanomaterials (Basel) 9:1146. doi: 10. 3390/nano9081146

Tasso, R., Augello, A., Carida, M., Postiglione, F., Tibiletti, M. G., Bernasconi, B., et al. (2009). Development of sarcomas in mice implanted with mesenchymal stem cells seeded onto bioscaffolds. Carcinogenesis 30, 150-157. doi: 10.1093/ carcin/bgn234

Tayeb, A. H., Amini, E., Ghasemi, S., and Tajvidi, M. (2018). Cellulose nanomaterials-binding properties and applications: a review. Molecules 23:2684. doi: 10.3390/molecules23102684

Teven, C. M., Liu, X., Hu, N., Tang, N., Kim, S. H., Huang, E., et al. (2011). Epigenetic regulation of mesenchymal stem cells: a focus on osteogenic and adipogenic differentiation. Stem Cells Int. 2011:201371. doi: 10.4061/2011/ 201371

Tharanathan, R. N., and Kittur, F. S. (2003). Chitin-the undisputed biomolecule of great potential. Crit. Rev. Food Sci. Nutr. 43, 61-87. doi: 10.1080/ 10408690390826455

Theodoridis, K., Aggelidou, E., Manthou, M., Demiri, E., Bakopoulou, A., and Kritis, A. (2019). Assessment of cartilage regeneration on 3D collagenpolycaprolactone scaffolds: evaluation of growth media in static and in perfusion bioreactor dynamic culture. Colloids Surf. B Biointerfaces 183:110403. doi: 10.1016/j.colsurfb.2019.110403

Toole, B. P. (2004). Hyaluronan: from extracellular glue to pericellular cue. Nat. Rev. Cancer 4, 528-539. doi: 10.1038/nrc1391

Tsudome, M., Deguchi, S., Tsujii, K., Ito, S., and Horikoshi, K. (2009). Versatile solidified nanofibrous cellulose-containing media for growth of extremophiles. Appl. Environ. Microbiol. 75, 4616-4619. doi: 10.1128/AEM.00519-519

Turk, S., Altinsoy, I., Celebi Efe, G., Ipek, M., Ozacar, M., and Bindal, C. (2018). 3D porous collagen/functionalized multiwalled carbon nanotube/chitosan/hydroxyapatite composite scaffolds for bone tissue engineering. Mater. Sci. Eng. C Mater. Biol. Appl. 92, 757-768. doi: 10.1016/j.msec.2018.07.020

Tyler, B., Gullotti, D., Mangraviti, A., Utsuki, T., and Brem, H. (2016). Polylactic acid (PLA) controlled delivery carriers for biomedical applications. Adv. Drug Deliv. Rev. 107, 163-175. doi: 10.1016/j.addr.2016.06.018

Valderrabano, V., Leumann, A., Rasch, H., Egelhof, T., Hintermann, B., and Pagenstert, G. (2017). Knee-to-Ankle mosaicplasty for the treatment of osteochondral lesions of the ankle joint. Am. J. Sports Med. 37, 105-111. doi: $10.1177 / 0363546509351481$

Van den Bulcke, A. I., Bogdanov, B., De Rooze, N., Schacht, E. H., Cornelissen, M., and Berghmans, H. (2000). Structural and rheological properties of methacrylamide modified gelatin hydrogels. Biomacromolecules 1, 31-38. doi: 10.1021/bm990017d

Venkatesan, J. K., Falentin-Daudre, C., Leroux, A., Migonney, V., and Cucchiarini, M. (2020). Biomaterial-Guided recombinant adeno-associated virus delivery from poly(Sodium Styrene Sulfonate)-Grafted Poly(varepsilon-Caprolactone) 
films to target human bone marrow aspirates. Tissue Eng. Part A 26, 450-459. doi: 10.1089/ten.TEA.2019.0165

Vollrath, F., and Knight, D. P. (2001). Liquid crystalline spinning of spider silk. Nature 410, 541-548. doi: 10.1038/35069000

Wang, G., Hu, X., Lin, W., Dong, C., and Wu, H. (2011). Electrospun PLGA-silk fibroin-collagen nanofibrous scaffolds for nerve tissue engineering. Vitro Cell Dev. Biol. Anim. 47, 234-240. doi: 10.1007/s11626-010-9381-4

Wang, J. Z., You, M. L., Ding, Z. Q., and Ye, W. B. (2019). A review of emerging bone tissue engineering via PEG conjugated biodegradable amphiphilic copolymers. Mater. Sci. Eng. C Mater. Biol. Appl. 97, 1021-1035. doi: 10.1016/j. msec.2019.01.057

Wang, K. H., Wan, R., Chiu, L. H., Tsai, Y. H., Fang, C. L., Bowley, J. F., et al. (2018). Effects of collagen matrix and bioreactor cultivation on cartilage regeneration of a full-thickness critical-size knee joint cartilage defects with subchondral bone damage in a rabbit model. PLoS One 13:e196779. doi: 10.1371/journal.pone. 0196779

Wang, Y., Rudym, D. D., Walsh, A., Abrahamsen, L., Kim, H. J., Kim, H. S., et al. (2008). In vivo degradation of three-dimensional silk fibroin scaffolds. Biomaterials 29, 3415-3428. doi: 10.1016/j.biomaterials.2008. 05.002

Wise, J. K., Yarin, A. L., Megaridis, C. M., and Cho, M. (2009). Chondrogenic differentiation of human mesenchymal stem cells on oriented nanofibrous scaffolds: engineering the superficial zone of articular cartilage. Tissue Eng. Part A 15, 913-921. doi: 10.1089/ten.tea.2008.0109

Wong, C. C., Chen, C. H., Chan, W. P., Chiu, L. H., Ho, W. P., Hsieh, F. J., et al. (2017). Single-Stage cartilage repair using platelet-rich fibrin scaffolds with autologous cartilaginous grafts. Am. J. Sports Med. 45, 3128-3142. doi: $10.1177 / 0363546517719876$

Wood, J. J., Malek, M. A., Frassica, F. J., Polder, J. A., Mohan, A. K., Bloom, E. T., et al. (2006). Autologous cultured chondrocytes: adverse events reported to the United States food and drug administration. J. Bone Joint Surg. Am. 88, 503-507. doi: 10.2106/JBJS.E.00103

Wu, C. C., Sheu, S. Y., Hsu, L. H., Yang, K. C., Tseng, C. C., and Kuo, T. F. (2017). Intra-articular Injection of platelet-rich fibrin releasates in combination with bone marrow-derived mesenchymal stem cells in the treatment of articular cartilage defects: an in vivo study in rabbits. J. Biomed. Mater. Res. B Appl. Biomater. 105, 1536-1543. doi: 10.1002/jbm.b.33688

Xia, C., Mei, S., Gu, C., Zheng, L., Fang, C., Shi, Y., et al. (2019). Decellularized cartilage as a prospective scaffold for cartilage repair. Mater. Sci. Eng. C Mater. Biol. Appl. 101, 588-595. doi: 10.1016/j.msec.2019.04.002

Xue, J. X., Feng, B., Zheng, R., Lu, Y., Zhou, G. D., Liu, W., et al. (2013). Engineering ear-shaped cartilage using electrospun fibrous membranes of gelatin/polycaprolactone. Biomaterials 34, 2624-2631. doi: 10.1016/j.biomat erials.2012.12.011

Yadav, V., Sun, L., Panilaitis, B., and Kaplan, D. L. (2015). In vitro chondrogenesis with lysozyme susceptible bacterial cellulose as a scaffold. J. Tissue Eng. Regen. Med. 9, E276-E288. doi: 10.1002/term.1644

Yamagata, K., Nakayamada, S., and Tanaka, Y. (2018). Use of mesenchymal stem cells seeded on the scaffold in articular cartilage repair. Inflamm. Regen. 38:4. doi: 10.1186/s41232-018-0061-61

Yamagata, M., Suzuki, S., Akiyama, S. K., Yamada, K. M., and Kimata, K. (1989). Regulation of cell-substrate adhesion by proteoglycans immobilized on extracellular substrates. J. Biol. Chem. 264, 8012-8018.

Yan, J., Chen, X., Pu, C., Zhao, Y., Liu, X., Liu, T., et al. (2020). Synovium stem cell-derived matrix enhances anti-inflammatory properties of rabbit articular chondrocytes via the SIRT1 pathway. Mater. Sci. Eng. C Mater. Biol. Appl. 106:110286. doi: 10.1016/j.msec.2019.110286

Yan, W., Xu, X., Xu, Q., Sun, Z., Jiang, Q., and Shi, D. (2020). Platelet-rich plasma combined with injectable hyaluronic acid hydrogel for porcine cartilage regeneration: a 6-month follow-up. Regen. Biomater. 7, 77-90. doi: 10.1093/rb/ rbz039

Yang, M., Shuai, Y., Zhou, G., Mandal, N., and Zhu, L. (2014). Nucleation of hydroxyapatite on Antheraea pernyi (A. pernyi) silk fibroin film. Biomed. Mater. Eng. 24, 731-740. doi: 10.3233/BME-130861

Yang, Q., Peng, J., Guo, Q., Huang, J., Zhang, L., Yao, J., et al. (2008). A cartilage ECM-derived 3-D porous acellular matrix scaffold for in vivo cartilage tissue engineering with PKH26-labeled chondrogenic bone marrowderived mesenchymal stem cells. Biomaterials 29, 2378-2387. doi: 10.1016/j. biomaterials.2008.01.037
Yang, X., Lu, Z., Wu, H., Li, W., Zheng, L., and Zhao, J. (2018). Collagenalginate as bioink for three-dimensional (3D) cell printing based cartilage tissue engineering. Mater. Sci. Eng. C Mater. Biol. Appl. 83, 195-201. doi: 10.1016/j. msec.2017.09.002

Yang, Y., Lin, H., Shen, H., Wang, B., Lei, G., and Tuan, R. S. (2018). Mesenchymal stem cell-derived extracellular matrix enhances chondrogenic phenotype of and cartilage formation by encapsulated chondrocytes in vitro and in vivo. Acta Biomater. 69, 71-82. doi: 10.1016/j.actbio.2017.12.043

Yang, Z., Shi, Y., Wei, X., He, J., Yang, S., Dickson, G., et al. (2010). Fabrication and repair of cartilage defects with a novel acellular cartilage matrix scaffold. Tissue Eng. Part C Methods 16, 865-876. doi: 10.1089/ten.TEC.2009.0444

Yin, Z., Chen, X., Zhu, T., Hu, J. J., Song, H. X., Shen, W. L., et al. (2013). The effect of decellularized matrices on human tendon stem/progenitor cell differentiation and tendon repair. Acta Biomater. 9, 9317-9329. doi: 10.1016/j.actbio.2013. 07.022

Yu, Y., Moncal, K. K., Li, J., Peng, W., Rivero, I., Martin, J. A., et al. (2016). Threedimensional bioprinting using self-assembling scalable scaffold-free "tissue strands" as a new bioink. Sci. Rep. 6:28714. doi: 10.1038/srep28714

Yuan, L., Li, B., Yang, J., Ni, Y., Teng, Y., Guo, L., et al. (2016). Effects of composition and mechanical property of injectable collagen I/II composite hydrogels on chondrocyte behaviors. Tissue Eng. Part A 22, 899-906. doi: 10. 1089/ten.TEA.2015.0513

Zehnder, T., Sarker, B., Boccaccini, A. R., and Detsch, R. (2015). Evaluation of an alginate-gelatine crosslinked hydrogel for bioplotting. Biofabrication 7:025001. doi: 10.1088/1758-5090/7/2/025001

Zhang, W. J., Liu, W., Cui, L., and Cao, Y. (2007). Tissue engineering of blood vessel. J. Cell Mol. Med. 11, 945-957. doi: 10.1111/j.1582-4934.2007.00099.x

Zhang, X., Yamaoka, K., Sonomoto, K., Kaneko, H., Satake, M., Yamamoto, Y., et al. (2014). Local delivery of mesenchymal stem cells with poly-lactic-coglycolic acid nano-fiber scaffold suppress arthritis in rats. PLoS One 9:e114621. doi: 10.1371/journal.pone.0114621

Zhang, Y., Yang, H., Shao, H., and Hu, X. (2010). Antheraea pernyi silk fiber: a potential resource for artificially biospinning spider dragline silk. J. Biomed. Biotechnol. 2010:683962. doi: 10.1155/2010/683962

Zheng, R., Duan, H., Xue, J., Liu, Y., Feng, B., Zhao, S., et al. (2014). The influence of Gelatin/PCL ratio and 3-D construct shape of electrospun membranes on cartilage regeneration. Biomaterials 35, 152-164. doi: 10.1016/j.biomaterials. 2013.09.082

Zheng, Y., Yang, J., Liang, J., Xu, X., Cui, W., Deng, L., et al. (2019). Bioinspired Hyaluronic Acid/Phosphorylcholine Polymer with Enhanced Lubrication and Anti-Inflammation. Biomacromolecules 20, 4135-4142. doi: 10.1021/acs. biomac.9b00964

Zhou, X. Z., Leung, V. Y., Dong, Q. R., Cheung, K. M., Chan, D., and Lu, W. W. (2008). Mesenchymal stem cell-based repair of articular cartilage with polyglycolic acid-hydroxyapatite biphasic scaffold. Int. J. Artif. Organs. 31, 480-489. doi: 10.1177/039139880803100603

Zhou, Y., Zimber, M., Yuan, H., Naughton, G. K., Fernan, R., and Li, W. J. (2016). Effects of human fibroblast-derived extracellular matrix on mesenchymal stem cells. Stem Cell Rev. Rep. 12, 560-572. doi: 10.1007/s12015-016-9671-9677

Zwingmann, J., Mehlhorn, A. T., Sudkamp, N., Stark, B., Dauner, M., and Schmal, H. (2007). Chondrogenic differentiation of human articular chondrocytes differs in biodegradable PGA/PLA scaffolds. Tissue Eng. 13, 2335-2343. doi: $10.1089 /$ ten.2006.0393

Zylinska, B., Silmanowicz, P., Sobczynska-Rak, A., Jarosz, L., and Szponder, T. (2018). Treatment of articular cartilage defects: focus on tissue engineering. Vivo 32, 1289-1300. doi: 10.21873/invivo.11379

Conflict of Interest: The authors declare that the research was conducted in the absence of any commercial or financial relationships that could be construed as a potential conflict of interest.

Copyright $\odot 2021$ Zhao, Hu, Wu, He, Wang, Huang, Shi, Liu, Ni, Pakvasa, Zhang, Fu, Qin, Li, Hagag, Wang, Sabharwal, Wagstaff, Reid, Lee, Wolf, El Dafrawy, Hynes, Strelzow, Ho, He and Athiviraham. This is an open-access article distributed under the terms of the Creative Commons Attribution License (CC BY). The use, distribution or reproduction in other forums is permitted, provided the original author(s) and the copyright owner(s) are credited and that the original publication in this journal is cited, in accordance with accepted academic practice. No use, distribution or reproduction is permitted which does not comply with these terms. 